ARTICLE

\title{
Remarkable catalytic activity of dinitrogen-bridged dimolybdenum complexes bearing NHC-based PCP-pincer ligands toward nitrogen fixation
}

\author{
Aya Eizawa', Kazuya Arashiba1, Hiromasa Tanaka², Shogo Kuriyama', Yuki Matsuo², Kazunari Nakajima1, \\ Kazunari Yoshizawa ${ }^{2,3}$ \& Yoshiaki Nishibayashi ${ }^{1}$
}

Intensive efforts for the transformation of dinitrogen using transition metal-dinitrogen complexes as catalysts under mild reaction conditions have been made. However, limited systems have succeeded in the catalytic formation of ammonia. Here we show that newly designed and prepared dinitrogen-bridged dimolybdenum complexes bearing $N$-heterocyclic carbene- and phosphine-based PCP-pincer ligands $\left[\left\{\mathrm{Mo}\left(\mathrm{N}_{2}\right)_{2}(P C P)\right\}_{2}\left(\mu-N_{2}\right)\right]$ (1) work as so far the most effective catalysts towards the formation of ammonia from dinitrogen under ambient reaction conditions, where up to 230 equiv. of ammonia are produced based on the catalyst. DFT calculations on $\mathbf{1}$ reveal that the PCP-pincer ligand serves as not only a strong $\sigma$-donor but also a $\pi$-acceptor. These electronic properties are responsible for a solid connection between the molybdenum centre and the pincer ligand, leading to the enhanced catalytic activity for nitrogen fixation.

\footnotetext{
${ }^{1}$ Department of Systems Innovation, School of Engineering, The University of Tokyo, Bunkyo-ku, Tokyo 113-8656, Japan. ${ }^{2}$ Institute for Materials Chemistry and Engineering, Kyushu University, Nishi-ku, Fukuoka 819-0395, Japan. ${ }^{3}$ Elements Strategy Initiative for Catalysts and Batteries, Kyoto University, Nishikyo-ku, Kyoto 615-8520, Japan. Correspondence and requests for materials should be addressed to K.Y. (email: kazunari@ms.ifoc.kyushu-u.ac.jp) or to Y.N. (email: ynishiba@sys.t.u-tokyo.ac.jp).
} 
$\mathrm{N}$ itrogen is an essential element for all living things on earth. Since most of the nitrogen atoms on earth exist as the form of inert dinitrogen gas, the fixing of molecular dinitrogen is necessary to be utilized. The industrial dinitrogen fixation system, called the Haber-Bosch process, plays an important role in producing ammonia from dinitrogen gas today $^{1}$. The operation of the process, however, requires high temperature and high pressure, resulting in large consumption of fossil fuels ${ }^{1}$. On the other hand, nitrogenases transform dinitrogen gas into ammonia under ambient reaction conditions, where the active sites of nitrogenases include iron, molybdenum and vanadium as essential transition metals ${ }^{2-5}$. Studies on the active sites of nitrogenases are considered to be important to elaborate an efficient artificial system for the catalytic ammonia formation from dinitrogen gas $^{6-8}$.

Despite intensive efforts for the transformation of dinitrogen gas using transition metal-dinitrogen complexes as catalysts under mild reaction conditions ${ }^{9-16}$, only a few systems have succeeded in the catalytic formation of ammonia from dinitrogen gas $^{17-28}$. In 2003, Yandulov and Schrock ${ }^{29-32}$ reported the first successful example of the catalytic conversion of dinitrogen gas into ammonia using a molybdenum-dinitrogen complex as a catalyst and in 2013 Peters and co-workers ${ }^{33-39}$ reported the iron-catalysed transformation using an iron-dinitrogen complex as a catalyst. We also found that several dinitrogen-bridged dimolybdenum complexes such as $\left[\left\{\mathrm{Mo}\left(\mathrm{N}_{2}\right)_{2}(\mathrm{PNP})\right\}_{2}\left(\mu-\mathrm{N}_{2}\right)\right]$ (2; $\quad$ PNP $=2,6$-bis(di-tert-butylphosphinomethyl)pyridine $)^{40-42}$ and molybdenum-nitride complexes bearing PNP-type pincer ligands ${ }^{43}$ or mer-tridentate triphosphine ${ }^{44}$ worked as more effective catalysts towards ammonia formation under ambient reaction conditions, where up to 63 equiv. of ammonia were produced based on the molybdenum atom of the catalyst.

During our continuous study, we have realized three promising clues to develop more effective catalysts. The first clue is the introduction of an electron-donating group to the pincer ligands to increase the backdonating ability of the molybdenum atom to the dinitrogen ligand. In fact, dinitrogen-bridged dimolybdenum complexes bearing the electron-donating group-substituted PNPpincer ligands worked as more effective catalysts in our previous reaction system ${ }^{41}$. The second clue is the inhibition of the dissociation of the pincer ligand from the molybdenum atom to increase the stability of the molybdenum complex. We generally

a

PCP-type pincer ligands (PCP, phosphorus-carbene-phosphorus)<smiles></smiles><smiles></smiles>

Bim-PCP $[1]$ $\mathbf{P}=\mathrm{P}^{\mathrm{t}} \mathrm{Bu}_{2}$<smiles></smiles>

Bim-PCP[2]

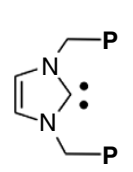

Im-PCP[1] $\mathbf{P}=\mathrm{P}^{t} \mathrm{Bu}_{2}$

b<smiles>[R]c1cc2c(cc1[R])N1CP3CN(C2)C(Cl)(Cl)P13</smiles>
$\underset{\substack{\mathrm{THF} \\ \mathrm{rt}, 17 \mathrm{~h}}}{\stackrel{\mathrm{Na}-\mathrm{Hg}}{\longrightarrow}} \mathrm{R}$

$\mathrm{R}=\mathrm{H} \quad\left[\mathrm{MoCl}_{3}(\mathrm{Bim}-\mathrm{PCP}[1])\right](\mathbf{3 a})$

$\mathrm{R}=\mathrm{Me}\left[\mathrm{MoCl}_{3}(\mathrm{Me}-\mathrm{Bim}-\mathrm{PCP}[1])\right](\mathbf{3 c})$

$$
\begin{aligned}
& R=H \quad\left[\left\{\operatorname{Mo}\left(N_{2}\right)_{2}(\operatorname{Bim}-P C P[1])\right\}_{2}\left(\mu-N_{2}\right)\right](1 \mathbf{a}), 37 \% \\
& R=\operatorname{Me}\left[\left\{\operatorname{Mo}\left(N_{2}\right)_{2}(\operatorname{Me}-\operatorname{Bim}-P C P[1])\right\}_{2}\left(\mu-N_{2}\right)\right](1 \mathrm{c}), 46 \%
\end{aligned}
$$

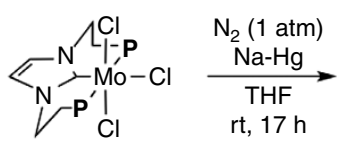

$\left[\mathrm{MoCl}_{3}(\mathrm{Im}-\mathrm{PCP}[2])\right](3 \mathbf{b})$

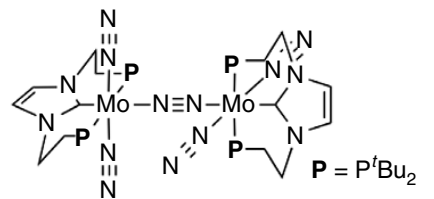

$\left[\left\{\mathrm{Mo}\left(\mathrm{N}_{2}\right)_{2}(\operatorname{Im}-\mathrm{PCP}[2])\right\}_{2}\left(\mu-\mathrm{N}_{2}\right)\right](\mathbf{1 b}), 53 \%$

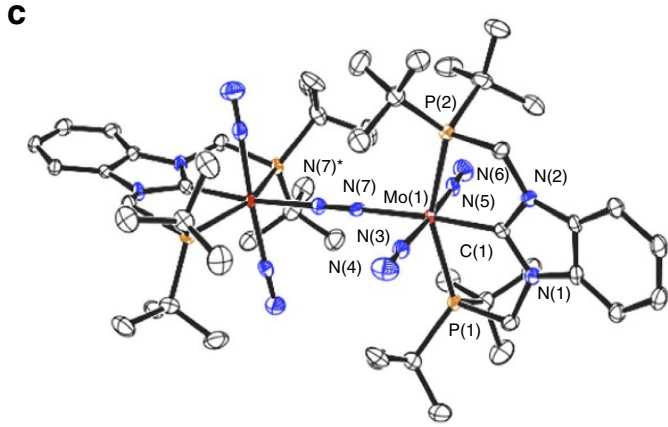

1a

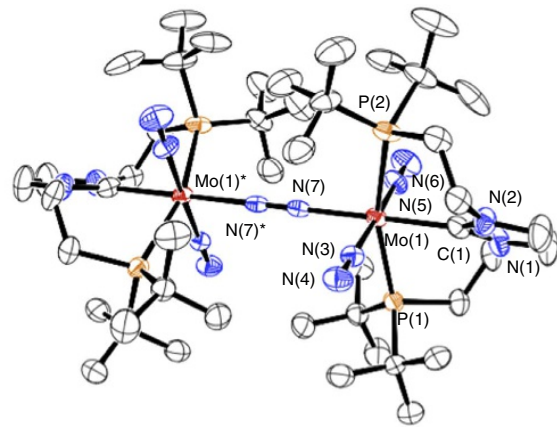

1b

Figure 1 | Design and synthesis of dinitrogen-bridged dimolybdenum complexes. (a) Newly designed PCP-type pincer ligands (PCP, phosphoruscarbene-phosphorus). (b) Synthesis of dinitrogen-bridged dimolybdenum complexes 1a-1c. (c) ORTEP drawings of $\mathbf{1 a}$ (left) and $\mathbf{1 b}$ (right). Thermal ellipsoids are shown at the 50\% probability level. Hydrogen atoms and solvated molecules are omitted for clarity. 
observed the dissociation of the PNP-pincer ligand after the ammonia formation in the catalytic reaction ${ }^{40}$. The third clue is the preservation of the dinitrogen-bridged dimolybdenum core to promote the catalytic ammonia formation from the coordinated dinitrogen ${ }^{43}$. Density functional theory (DFT) calculations demonstrated that the dinitrogen-bridged dimolybdenum structure plays a vital role in the protonation of a dinitrogen ligand, where one molybdenum moiety of the dinuclear molybdenum-dinitrogen complex works as a mobile ligand to the other molybdenum moiety as an active site $e^{43}$.

Taking account of these clues, we have now planned to design an N-heterocyclic carbene- (NHC-) 45,46 and phosphine-based PCP-type pincer ligand (a PCP-type pincer ligand composed of NHC and two phosphines) as a tridentate ligand in place of the so far employed PNP-type pincer ligand for preparing a new molybdenum-dinitrogen complex. It is known that NHC works as a stronger electron-donating ligand than pyridine and binds to a transition metal centre more strongly than pyridine ${ }^{47,48}$. In this article, we demonstrate that dinitrogen-bridged dimolybdenum complexes bearing PCP-pincer ligands $\left[\left\{\mathrm{Mo}\left(\mathrm{N}_{2}\right)_{2}(\mathrm{PCP})\right\}_{2}\right.$ $\left(\mu-\mathrm{N}_{2}\right)$ ] (1) worked as effective catalysts towards ammonia formation under ambient reaction conditions, where up to 230 equiv. of ammonia were produced based on the catalyst (115 equiv. of ammonia based on the molybdenum atom of the catalyst). This is so far the most effective catalytic reduction of dinitrogen gas into ammonia under ambient reaction conditions using transition metal-dinitrogen complexes as catalysts.

\section{Results}

Preparation and characterization of 1 . On the basis of our proposal, we designed two types of dinitrogen-bridged dimolybdenum complexes bearing PCP-type pincer ligands with two tert-butyl groups on each phosphorus atom (Fig. 1a). One is the complex bearing methylene linkers between the NHC skeleton and the phosphorus atom, where a similar PCP-pincer ligand bearing two phenyl groups on each phosphorus atom has quite recently been reported by Rieger and co-workers ${ }^{49}$. The other is the complex bearing ethylene linkers, where similar PCP-pincer ligands bearing two phenyl groups on each phosphorus atom have already been reported by some research groups ${ }^{50-55}$.

According to our previous procedure ${ }^{40-42}$, we newly prepared three dinitrogen-bridged dimolybdenum complexes bearing the PCP-type pincer ligands. Treatment of $\left[\mathrm{MoCl}_{3}(\mathrm{PCP})\right]$ (3a, $\mathrm{PCP}=1,3$-bis ((di-tert-butylphosphino)methyl)benzimidazol-2ylidene (Bim-PCP[1]); 3b, PCP = 1,3-bis(2-(di-tert-butylphosphino) ethyl)imidazol-2-ylidene (Im-PCP[2]); 3c, PCP = 5,6-dimethyl-1, 3-bis((di-tert-butylphosphino)methyl)benzimidazol-2-ylidene (Me-Bim-PCP[1])) with 6 equiv. of $\mathrm{Na}-\mathrm{Hg}$ in tetrahydrofuran (THF) at room temperature for $17 \mathrm{~h}$ under an atmospheric pressure of molecular dinitrogen gave the corresponding dinitrogen-bridged dimolybdenum complexes $\left[\left\{\mathrm{Mo}\left(\mathrm{N}_{2}\right)_{2}(\mathrm{PCP})\right\}_{2}\right.$ $\left.\left(\mu-\mathrm{N}_{2}\right)\right] \quad(\mathbf{1 a} ; \quad \mathrm{PCP}=\mathrm{Bim}-\mathrm{PCP}[1], \mathbf{1 b} ; \quad \mathrm{PCP}=\mathrm{Im}-\mathrm{PCP}[2], \quad \mathbf{1 c}$; $\mathrm{PCP}=\mathrm{Me}-\mathrm{Bim}-\mathrm{PCP}[1])$ in $37 \%, 53 \%$ and $46 \%$ yields, respectively (Fig. 1b). Detailed synthetic procedures for ligand precursors are included in Supplementary Methods and synthetic procedures for metal precursors $\mathbf{3 a}-\mathbf{3} \mathbf{c}$ are included in Methods section. These dinitrogen-bridged dimolybdenum complexes were characterized by ${ }^{1} \mathrm{H}$ and ${ }^{31} \mathrm{P}\left\{{ }^{1} \mathrm{H}\right\} \quad$ NMR. Detailed molecular structures of these complexes 1a-1c were determined by X-ray crystallography (Fig 1c for $\mathbf{1 a}$ and $\mathbf{1 b}$; Supplementary Fig. 1 for 1c), which were similar to those of the dinitrogenbridged dimolybdenum complexes bearing PNP-pincer ligands ${ }^{40-}$ 42 . However, the bond lengths, the bond angles and dihedral angles were significantly different between $\mathbf{1 a}$ and $\mathbf{1 b}$ according to the nature of the linkers in the PCP-pincer ligands
(Supplementary Tables 3 and 4). The bond lengths defined by $\mathrm{Mo}(1)-\mathrm{C}(1)$ of $\mathbf{1 a}$ and $\mathbf{1 b}$ were 2.064(2) $\AA$ and 2.153(4) $\AA$, respectively, and the bond angles defined by $\mathrm{P}(1)-\mathrm{Mo}(1)-\mathrm{P}(2)$ of $\mathbf{1 a}$ and $\mathbf{1 b}$ were $153.95(3)^{\circ}$ and $163.18(8)^{\circ}$, respectively. On the other hand, the dihedral angles defined by $\mathrm{N}(1)-\mathrm{C}(1)-\mathrm{Mo}(1)-\mathrm{N}(5)$ of $\mathbf{1 a}$ and $\mathbf{1 b}$ were $82.35(5)^{\circ}$ and $43.74(7)^{\circ}$, respectively. The shortened bond length of $\mathrm{Mo}(1)-\mathrm{C}(1)$ of la suggests the stronger $\pi$-backdonation from the molybdenum centre to the NHC unit due to the almost-perpendicular orientation of the NHC unit. On the other hand, the longer $\mathrm{CH}_{2}$ linker of Im-PCP[2] forces the twisted coordination of the NHC and is likely to weaken the $\pi$-backdonation in $\mathbf{1 b}$. Further information on this topic is discussed based on DFT calculations (vide infra).

Infrared spectra of $\mathbf{1 a - 1 c}$ in the solid state showed a strong absorption peak assignable to terminal dinitrogen ligands at $1,978,1,911$ and $1,969 \mathrm{~cm}^{-1}$ respectively. The single peak of each complex corresponds to the dinitrogen-bridged dimolybdenum structure, as determined by X-ray crystallography. Compared with the infrared spectrum of $\mathbf{1 b}$, those of $\mathbf{1 a}$ and $\mathbf{1 c}$ showed the peak at much higher frequency due to the strong $\pi$-backdonation from the molybdenum centre to the NHC. The infrared spectra of $\mathbf{1 a}$ and 1c in THF solution showed one strong absorption peak assignable to terminal dinitrogen ligands at 1,979 and $1,973 \mathrm{~cm}^{-1}$, respectively. Comparison of the infrared spectra of 1a and $\mathbf{1 c}$ in the solid state with that in the solution state indicates that the dinitrogen-bridged dinuclear structures of $\mathbf{1 a}$ and 1c are preserved even in solution. Furthermore, the ${ }^{15} \mathrm{~N}\left\{{ }^{1} \mathrm{H}\right\}$ NMR spectrum of ${ }^{15} \mathrm{~N}_{2}$-labelled 1a in $\mathrm{C}_{6} \mathrm{D}_{6}$ under ${ }^{15} \mathrm{~N}_{2}$ showed two singlet and one doublet signals; $\delta 7.2$ (s, Mo-N $\equiv N-\mathrm{Mo}$ ), -13.0 $\left(\mathrm{d},{ }^{1} J_{\mathrm{N}-\mathrm{N}}=5.4 \mathrm{~Hz}, \mathrm{Mo}-\mathrm{N} \equiv N\right),-32.0$ (br s, Mo-N $\left.\equiv \mathrm{N}\right)$, which are consistent with the dinuclear structure (Fig. 2a) ${ }^{40,56}$. In contrast, the infrared spectrum of $\mathbf{1 b}$ in THF solution showed two peaks assignable to terminal dinitrogen ligands, suggesting that the structure of $\mathbf{1 b}$ in THF is no longer the same with that in the solid state. To obtain more information on real species of $\mathbf{1 b}$ in the THF solution, the ${ }^{15} \mathrm{~N}\left\{{ }^{1} \mathrm{H}\right\}$ NMR spectrum of 1b was measured in THF- $d_{8}$ solution under an atmospheric pressure of ${ }^{15} \mathrm{~N}_{2}$ gas. The spectrum showed two doublet and two double triplet signals; $\delta 1.2\left(\mathrm{~d},{ }^{1} J_{\mathrm{N}-\mathrm{N}}=6.0 \mathrm{~Hz}\right.$, $\mathrm{Mo}-\mathrm{N} \equiv N($ equatorial $)),-20.8\left(\mathrm{~d},{ }^{1} J_{\mathrm{N}-\mathrm{N}}=6.1 \mathrm{~Hz}, \mathrm{Mo}-\mathrm{N} \equiv N(\right.$ axial $\left.)\right)$, $-27.8\left(\mathrm{dt},{ }^{1} J_{\mathrm{N}-\mathrm{N}}=6.0 \mathrm{~Hz}\right.$ and ${ }^{2} J_{\mathrm{N}-\mathrm{P}}=1.6 \mathrm{~Hz}, \quad \mathrm{Mo}-\mathrm{N} \equiv \mathrm{N}$ (equatorial)), $-30.5\left(\mathrm{dt},{ }^{1} J_{\mathrm{N}-\mathrm{N}}=6.1 \mathrm{~Hz}\right.$ and ${ }^{2} J_{\mathrm{N}-\mathrm{P}}=2.3 \mathrm{~Hz}$, Mo- $N \equiv \mathrm{N}$ (axial); Fig. 2b), demonstrating the formation of the corresponding mononuclear dinitrogen complex $\left[\mathrm{Mo}\left(\mathrm{N}_{2}\right)_{3}\right.$ $(\mathrm{Im}-\mathrm{PCP}[2])]\left(\mathbf{1 b}^{\prime}\right)$ in THF. In fact, these spectroscopic features of $\mathbf{1} \mathbf{b}^{\prime}$ in THF are consistent with those of similar mononuclear dinitrogen complexes such as mer- $\left[\mathrm{Mo}\left(\mathrm{N}_{2}\right)_{3} \mathrm{~L}_{3}\right]$ structures $^{57,58}$. The instability of $\mathbf{1 b}$ in solution may be derived from the steric repulsion between the two molybdenum moieties bearing Im-PCP[2].

As shown in Fig. 1, we prepared two types of the PCP-pincer ligands, where Bim-PCP[1] has a benzimidazol-2-ylidene skeleton and Im-PCP[2] has an imidazol-2-ylidene skeleton. Unfortunately, we were unable to synthesize the corresponding two PCP-pincer ligands based on the same NHC skeleton bearing linkers of the different lengths between the NHC skeleton and each phosphorus atom (Bim-PCP[2] and Im-PCP[1] in Fig. 1a). However, we consider that the presence or absence of benzene ring has little influence on either the thermodynamic stability of the Mo-N $\equiv \mathrm{N}-\mathrm{Mo}$ structures or the electron-donating ability of the pincer ligands for the following reasons. To assess the influence of the benzene moiety in Bim-PCP[1] on the thermodynamic stability of the dinitrogen-bridged dimolybdenum structure, we calculated a model complex $\left[\left\{\mathrm{Mo}\left(\mathrm{N}_{2}\right)_{2}(\mathrm{Im}\right.\right.$ $\left.\operatorname{PCP}[1])\}_{2}\left(\mu-\mathrm{N}_{2}\right)\right]$, where the benzimidazol-2-ylidene skeleton in Bim-PCP [1] is replaced by the imidazol-2-ylidene skeleton. The optimized distance of the $\mathrm{Mo}-\mathrm{N}_{2}$ (bridging) bond and its bond 
a
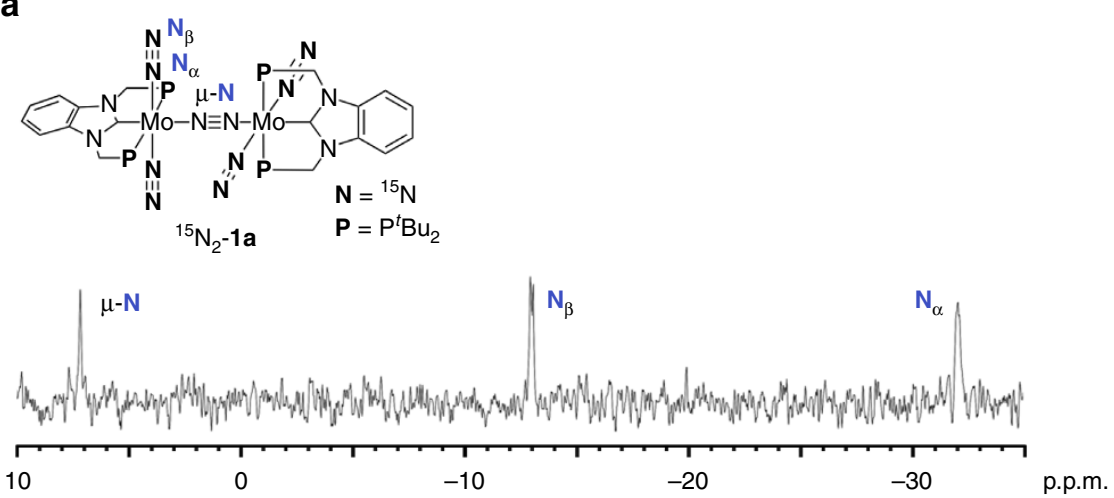

b
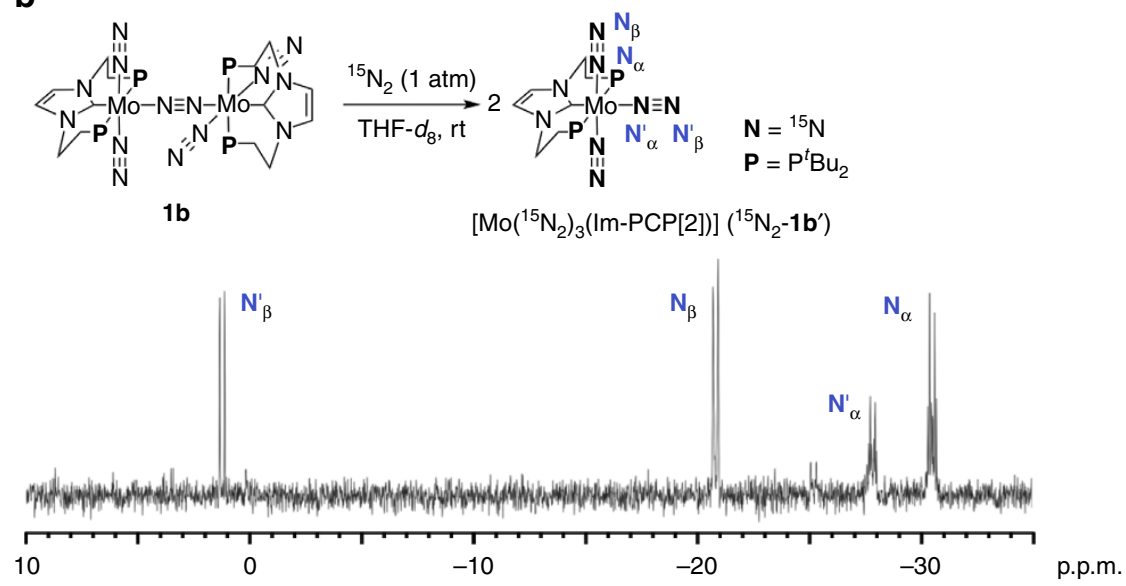

Figure $2 \mid{ }^{\mathbf{1 5}} \mathbf{N}\left\{{ }^{\mathbf{1}} \mathbf{H}\right\} \mathbf{N M R}$ spectra of 1a and $\mathbf{1 b}$. (a) ${ }^{15} \mathrm{~N}\left\{{ }^{1} \mathrm{H}\right\} \mathrm{NMR}$ spectrum of ${ }^{15} \mathrm{~N}_{2}-\mathbf{1 a}$ in $\mathrm{C}_{6} \mathrm{D}_{6}$ under ${ }^{15} \mathrm{~N}_{2}$. (b) ${ }^{15} \mathrm{~N}\left\{{ }^{1} \mathrm{H}\right\} \mathrm{NMR}$ spectrum of ${ }^{15} \mathrm{~N}_{2}-\mathbf{1} \mathbf{b}^{\prime}$ in $T H F-$ $d_{8}$ under ${ }^{15} \mathrm{~N}_{2}$.

dissociation energy (BDE) are $2.105 \AA$ and $18.4 \mathrm{kcal} \mathrm{mol}^{-1}$, respectively, both of which are almost identical to those calculated for $1 \mathrm{a}\left(2.108 \AA\right.$ and $\left.18.8 \mathrm{kcal} \mathrm{mol}^{-1}\right)$. The definition of BDE is described in the Methods section. On the other hand, Tuczek and co-workers ${ }^{52,53}$ have previously prepared two PCP ligands based on benzimidazol-2-ylidene and imidazol-2-ylidene, where these ligands have similar $\sigma$-donating ability. Gusev ${ }^{59,60}$ has previously estimated the donor ability of various NHC ligands based on the computational evaluation of $v_{\mathrm{CO}}(\mathrm{A} 1)$ of $\left[\mathrm{Ni}(\mathrm{CO})_{3}(\mathrm{NHC})\right]$. The author showed that 1,3-dimethylbenzimidazol-2-ylidene and 1,3-dimethylimidazol-2-ylidene have almost the same values of $v_{\mathrm{CO}}\left(2,057\right.$ and $2,054 \mathrm{~cm}^{-1}$, respectively), suggesting that the electron-donating ability of the NHC ligands was scarcely influenced by the difference between benzimidazol-2-ylidene and imidazol-2-ylidene. We therefore expect that the introduction of a benzene ring to the NHC skeleton little influences either the thermodynamic stability of the Mo-N $\equiv \mathrm{N}-$ Mo structure or the electron-donating ability of the pincer ligand.

We then performed DFT calculations to elucidate how the length of linkers connecting the NHC skeleton with the $\mathrm{P}^{t} \mathrm{Bu}_{2}$ groups in Bim-PCP[1] and Im-PCP[2] influences the thermodynamic stability of the dinitrogen-bridged dimolybdenum structures in $\mathbf{1 a}$ and $\mathbf{1 b}$. Figure 3 shows optimized structures of dimolybdenum complexes $\mathbf{1 a}$ and $\mathbf{1 b}$. The $\mathrm{N} \equiv \mathrm{N}$ stretching frequencies of terminal dinitrogen ligands calculated for 1a $\left(2,012 \mathrm{~cm}^{-1}\right)$ and $\mathbf{1 b}\left(1,969 \mathrm{~cm}^{-1}\right)$ reproduced the experimental trend. The Mo-N and $\mathrm{N}-\mathrm{N}$ distances of a terminal dinitrogen ligand are calculated to be 2.032 and $1.137 \AA$ for $1 \mathrm{a}$ and 2.016 and $1.142 \AA$ for $1 \mathbf{b}$, respectively, indicating that the terminal dinitrogen ligand in $\mathbf{1 b}$ is more activated than that in $\mathbf{1 a}$. As a result, the $\mathrm{BDE}$ of a $\mathrm{Mo}-\mathrm{N}_{2}$ (terminal) of $1 \mathrm{a}\left(11.9 \mathrm{kcal} \mathrm{mol}^{-1}\right)$ is considerably lower than that of $\mathbf{1 b}\left(16.7 \mathrm{kcal} \mathrm{mol}^{-1}\right)$. On the other hand, the Mo-N distance of the bridging dinitrogen ligand of $\mathbf{1 a}(2.108 \AA)$ is shorter than that of $\mathbf{1 b}(2.133 \AA)$. The BDE of the Mo- $\mathrm{N}_{2}$ (bridging) bond of $1 \mathrm{a}$ is $18.8 \mathrm{kcal} \mathrm{mol}^{-1}$, which is more than twice as high as that of $\mathbf{1 b}, 9.0 \mathrm{kcal} \mathrm{mol}^{-1}$. The very low BDE of the Mo- $\mathrm{N}_{2}$ (bridging) bond of $\mathbf{1 b}$ can be associated with the experimental observation that the dinuclear complex $\mathbf{1 b}$ is labile to be separated into two mononuclear complexes in solution.

Differences in thermodynamic stability of the Mo-N $\equiv \mathrm{N}-\mathrm{Mo}$ structure between 1a and $\mathbf{1 b}$ can be rationalized by optimized structures of the corresponding mononuclear dinitrogen complexes. Figure 4 presents space-filling models of $\left[\mathrm{Mo}\left(\mathrm{N}_{2}\right)_{3}(\mathrm{PCP})\right]$ $\left(\mathbf{l a}^{\prime} ; \mathrm{PCP}=\mathrm{Bim}-\mathrm{PCP}[1], \mathbf{1}^{\prime} ; \mathrm{PCP}=\mathrm{Im}-\mathrm{PCP}[2]\right)$. Comparison of the Mo-N distance for the equatorial dinitrogen ligand of $\mathbf{1 a}^{\prime}$ $(2.084 \AA)$ with that of $\mathbf{1 b}^{\prime}(2.041 \AA)$ suggests that $\mathbf{1}^{\prime}$ bearing Im-PCP [2] strongly binds dinitrogen at the equatorial position. Contrary to the BDEs of the $\mathrm{Mo}-\mathrm{N}_{2}$ (bridging) bond calculated for dinuclear complexes $\mathbf{1 a}$ and $\mathbf{1 b}$, the $\mathrm{BDE}$ of the Mo- $\mathrm{N}_{2}$ (equatorial) bond of $\mathbf{1 b}^{\prime}\left(21.5 \mathrm{kcal} \mathrm{mol}^{-1}\right)$ is almost the same with that of $\mathbf{1 a}^{\prime}\left(21.2 \mathrm{kcal} \mathrm{mol}^{-1}\right)$. The dramatic decrease in the $\mathrm{Mo}-\mathrm{N}_{2}$ (equatorial) $\mathrm{BDE}$ of $\mathbf{1} \mathbf{b}^{\prime}$ in the formation of the dinuclear structure can be ascribed to steric hindrance caused by the tert-butyl groups on each phosphorus atom in Im-PCP[2]. The optimized structure of $1 \mathbf{a}^{\prime}$ bearing Bim-PCP[1] with the methylene linkers has the $\mathrm{P}-\mathrm{Mo}-\mathrm{P}$ bond angle of $151.2^{\circ}$, while that of $\mathbf{1} \mathbf{b}^{\prime}$ bearing Im-PCP[2] with the ethylene linkers has the bond angle of $164.3^{\circ}$. The extension of the $\mathrm{CH}_{2}$ linkers in $\mathbf{1 \mathbf { b } ^ { \prime }}$ forces the tert-butyl groups on each phosphorus atom in 


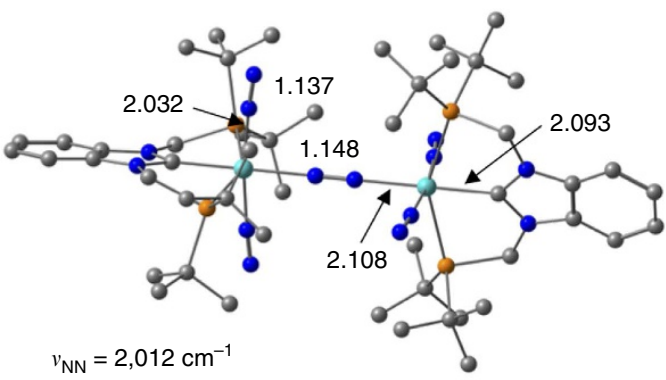

1a

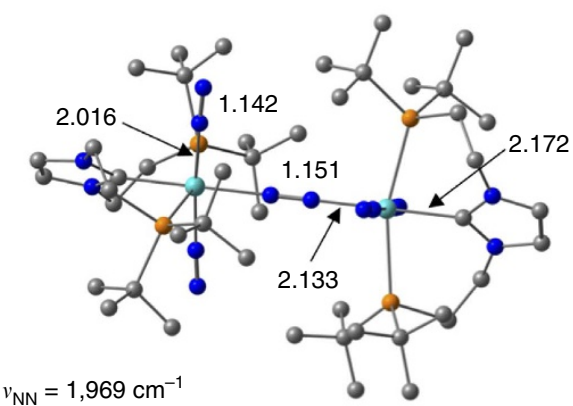

$1 \mathrm{~b}$

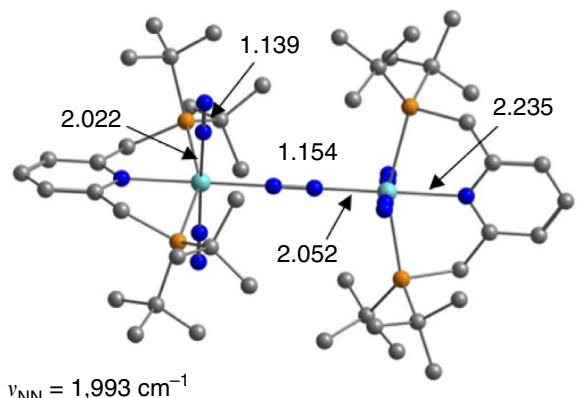

$v_{\mathrm{NN}}=1,993 \mathrm{~cm}^{-1}$

2

Figure 3 | Optimized structures of dinuclear complexes. Bond distances are shown in $\AA$. The values of $v_{\mathrm{NN}}$ present the $\mathrm{N} \equiv \mathrm{N}$ stretching frequencies of terminal dinitrogen ligands. Hydrogen atoms are omitted for clarity.

Im-PCP[2] to project towards the space surrounding the equatorial dinitrogen ligand (Fig. 4). As a result, the formation of a thermodynamically stable dimolybdenum complex bearing Im-PCP[2] is encumbered by steric repulsions between tert-butyl groups in two mononuclear molybdenum units facing each other.

Catalytic nitrogen fixation using 1 as catalysts. The catalytic reduction of molecular dinitrogen into ammonia using 1 as catalysts was carried out according to the following procedure of the previous method ${ }^{40-42}$. To a mixture of 1 and 2,6-lutidinium trifluoromethanesulfonate (96 equiv. to $\mathbf{1}$; [LutH]OTf) as a proton source in toluene was added a solution of metallocene (72 equiv. to 1 ) as a reductant in toluene via a syringe pump at room temperature over a period of $1 \mathrm{~h}$, followed by stirring at room temperature for another $19 \mathrm{~h}$ under an atmospheric pressure of dinitrogen. After the reaction, the amounts of ammonia and molecular dihydrogen were determined by indophenol method ${ }^{61}$ and gas chromatography (GC), respectively. The yields of ammonia and molecular dihydrogen were calculated based on the metallocene. Typical results are shown in Table 1. In all cases, no formation of other products such as hydrazine was observed at all.
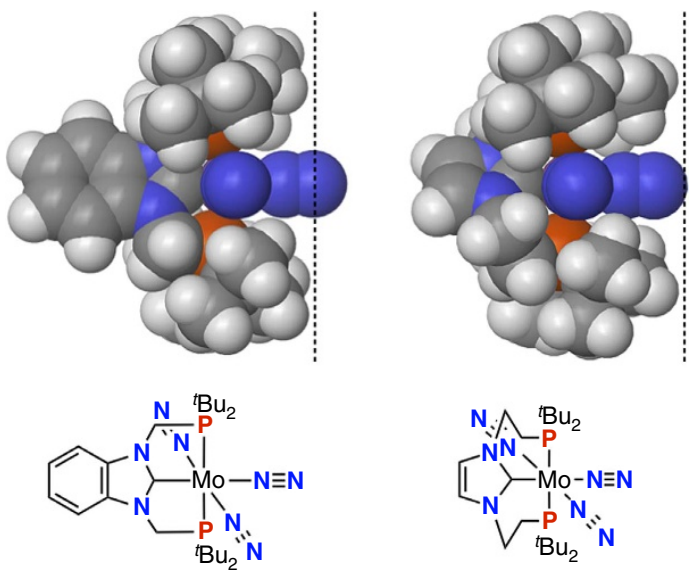

$\angle \mathrm{P}-\mathrm{Mo}-\mathrm{P}=151.2^{\circ}$

$1 a^{\prime}$

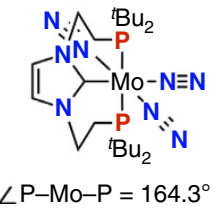

$1 b^{\prime}$

Figure 4 | Space-filling models of mononuclear Mo-N $\mathbf{2}$ complexes $1 a^{\prime}$ and $\mathbf{1} \mathbf{b}^{\prime}$. The dashed lines represent the projection of tert-butyl groups on phosphine atoms.

First, we carried out the catalytic reaction in the presence of 1a as a catalyst using either cobaltocene $\left(\mathrm{CoCp} \mathrm{p}_{2} ; \mathrm{Cp}=\eta^{5}-\mathrm{C}_{5} \mathrm{H}_{5}\right)$, decamethylchromocene $\left(\mathrm{CrCp}^{*}{ }_{2} ; \mathrm{Cp}^{*}=\eta^{5}-\mathrm{C}_{5} \mathrm{Me}_{5}\right)$, and decamethylcobaltocene $\left(\mathrm{CoCp}_{2}^{*}\right)$ as reductants, to produce $5.7,17.6$ and 11.8 equiv. of ammonia based on the catalyst, respectively (Table 1, runs 1-3). In the absence of a reductant, only 0.2 equiv. of ammonia were produced based on 1a (Table 1, run 4). We have previously obtained the result that 12.2 equiv. of ammonia were produced based on the catalyst from the reaction with $\mathrm{CrCp}^{*}{ }_{2}$ as a reductant in the presence of $\left[\left\{\mathrm{Mo}\left(\mathrm{N}_{2}\right)_{2}(\mathrm{PNP})\right\}_{2}\right.$ $\left.\left(\mu-N_{2}\right)\right] 2$ as a catalyst (Table 1 , run 9$)^{40}$. This means that 1a promoted the catalytic nitrogen fixation more effectively than 2. Separately, we confirmed the direct conversion of molecular dinitrogen into ammonia by using ${ }^{15} \mathrm{~N}_{2}$ gas in place of normal ${ }^{14} \mathrm{~N}_{2}$ gas (see Supplementary Methods for detailed procedure).

In stark contrast to the catalytic activity of $\mathbf{1 a}, \mathbf{1} \mathbf{b}$ did not work so effectively towards the formation of ammonia under the same reaction conditions. When $\mathrm{CoCp}_{2}, \mathrm{CrCp}_{2}{ }_{2}$ and $\mathrm{CoCp}_{2}{ }_{2}$ were used as reductants, only $1.4,3.2$ and 2.9 equiv. of ammonia were produced based on the catalyst, respectively (Table 1, runs 5-7). In the absence of a reductant, 1.5 equiv. of ammonia were produced based on $\mathbf{1 b}$ (Table 1 , run 8 ).

Next, we investigated the influence of a proton source in the catalytic nitrogen fixation using $\mathbf{1 a}$ as a catalyst. Typical results are shown in Table 2, where larger amounts of both reductant and proton source were employed in order to sharpen the difference among the results (see Supplementary Methods for the detailed procedure). The catalytic reaction using larger amounts of reductant $\mathrm{CrCp}_{2}^{*}$ (360 equiv. to 1a) and proton source [LutH]OTf (480 equiv. to 1a) afforded 79 equiv. of ammonia based on the catalyst (Table 2, run 1). When 2-picolinium trifluoromethanesulfonate $([\mathrm{PicH}] \mathrm{OTf} ; \mathrm{Pic}=2$-picoline $)$ was used in place of [LutH]OTf, only a small amount of ammonia was produced based on the catalyst (Table 2, run 2). On the other hand, 2,4,6-collidinium trifluoromethanesulfonate ([ColH]OTf; $\mathrm{Col}=2,4,6$-collidine) worked rather effectively, where 61 equiv. of ammonia were produced (Table 2, run 3 ). When a noncoordinating anion $\mathrm{BAr}_{4}^{\mathrm{F}}-\left(\mathrm{Ar}^{\mathrm{F}}=3,5-\left(\mathrm{CF}_{3}\right)_{2} \mathrm{C}_{6} \mathrm{H}_{3}\right)$ was used in place of $\mathrm{OTf}^{-}$in [LutH]OTf, only a small amount of ammonia was produced (Table 2, run 4). These results indicate that the use of [LutH]OTf as a proton source is an essential factor to achieve the high performance of $\mathbf{1 a}$ as a catalyst. 
Table 1 | Catalytic formation of ammonia from dinitrogen gas employing 1a or $1 \mathrm{~b}$ as a catalyst.

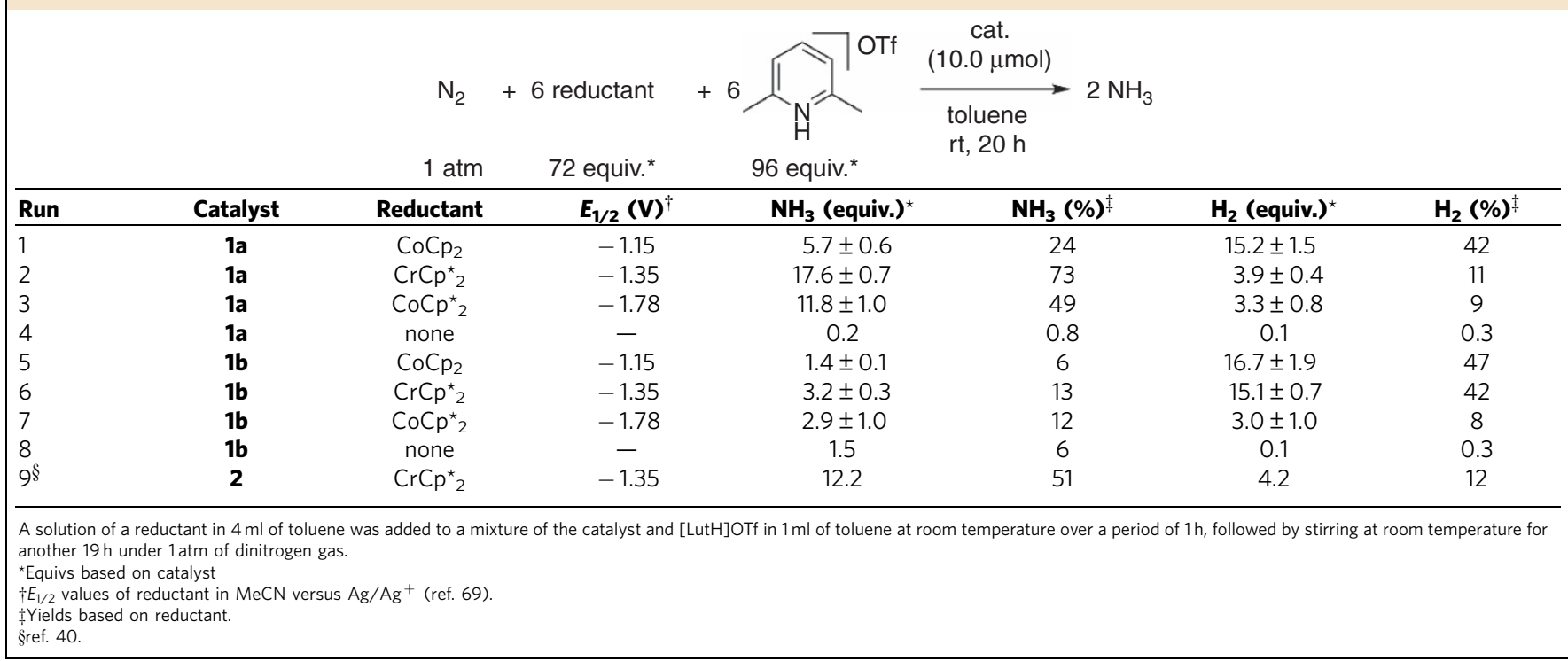

Table 2 | Catalytic formation of ammonia from dinitrogen gas using 1a as a catalyst.

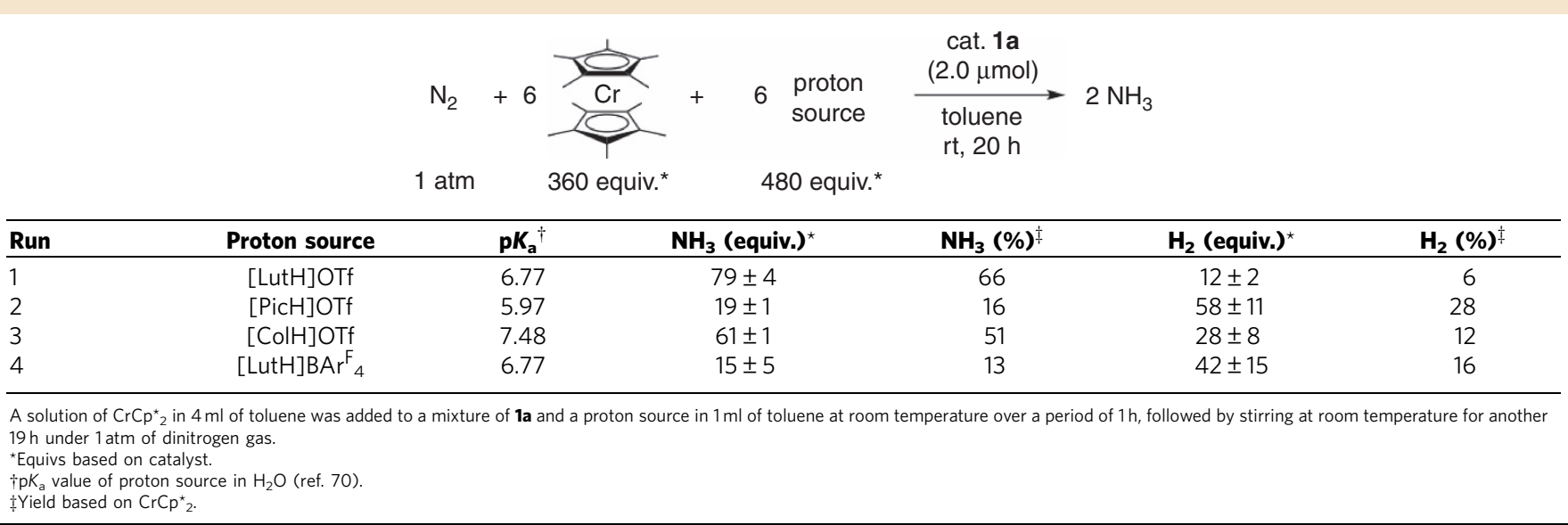

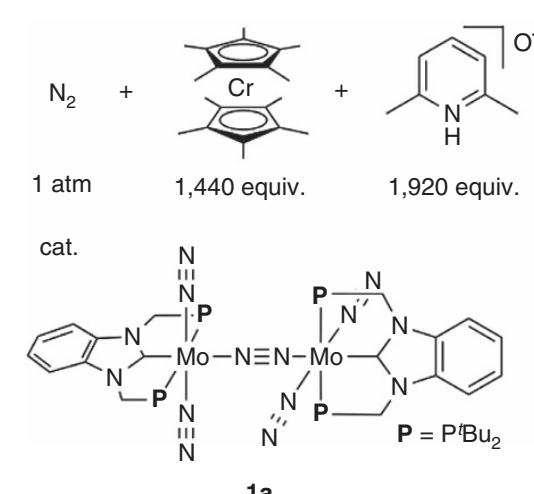

$1 \mathrm{a}$

$\mathrm{NH}_{3} \quad(2.0 \pm 0.2) \times 10^{2}$ equiv. (42\%)

$\mathrm{H}_{2} \quad(1.0 \pm 0.4) \times 10^{2}$ equiv. (14\%)

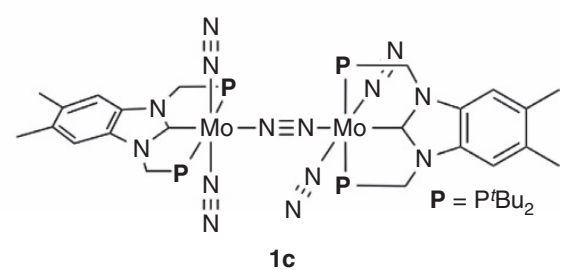

$\mathrm{NH}_{3} \quad 2.3 \times 10^{2}$ equiv. $(48 \%)$

$\mathrm{H}_{2} \quad 1.2 \times 10^{2}$ equiv. $(16 \%)$

Figure 5 | Catalytic formation of ammonia using larger amounts of a reductant and a proton source in the presence of 1a or 1c as a catalyst. A solution of $\mathrm{CrCp}_{2}{ }_{2}$ in $5 \mathrm{ml}$ of toluene was added to a mixture of the catalyst and [LutH]OTf in $1 \mathrm{ml}$ of toluene at room temperature over a period of $1 \mathrm{~h}$ (for $\mathbf{1 a}$ ) or $5 \mathrm{~h}$ (for $\mathbf{1 c}$ ), followed by stirring at room temperature for another $19 \mathrm{~h}$ (for $\mathbf{1 a}$ ) or $15 \mathrm{~h}$ (for $\mathbf{1 c}$ ) under $1 \mathrm{~atm}$ of dinitrogen gas. The amounts of ammonia and hydrogen (equiv.) are based on the catalyst. Yields are based on $\mathrm{CrCp}_{2}{ }_{2}$. 
On the basis of the results shown in Tables 1 and 2, we carried out the catalytic reaction using much larger amounts of $\mathrm{CrCp}_{2}^{*}$ and [LutH]OTf as a reductant and a proton source to the catalyst, respectively (see Supplementary Methods for the detailed procedure). The reaction using 1,440 equiv. of $\mathrm{CrCp}_{2}^{*}$ as a reductant and 1,920 equiv. of [LutH]OTf as a proton source in the presence of $\mathbf{1 a}$ as a catalyst under ambient reaction conditions gave $2.0 \times 10^{2}$ equiv. of ammonia based on the catalyst (Fig. 5). The catalytic activity of 1a towards the formation of ammonia is an order of magnitude greater than that of $\left[\left\{\mathrm{Mo}\left(\mathrm{N}_{2}\right)_{2}(\mathrm{PNP})\right\}_{2}\right.$ $\left.\left(\mu-\mathrm{N}_{2}\right)\right] 2$ (up to 23 equiv. of ammonia based on 2). Ammonia was obtained in $42 \%$ yield together with molecular dihydrogen (14\% yield). Furthermore, a higher catalytic activity has been achieved when 1c was used as a catalyst, where up to $2.3 \times$ $10^{2}$ equiv. of ammonia based on the catalyst were produced under similar reaction conditions (Fig. 5). We have not yet obtained the exact reason why $\mathbf{1 c}$ worked as the more effective catalyst than 1a, but we consider that the introduction of two methyl groups to the benzimidazol-2-ylidene skeleton in the PCP-pincer ligand may increase the backdonating ability of molybdenum centres to the coordinated dinitrogen ligand and activated the terminal dinitrogen ligands more strongly than 1a. The infrared spectrum of $1 \mathrm{c}$ in the solid state showed a strong absorption peak assignable to terminal dinitrogen ligands at $1,969 \mathrm{~cm}^{-1}$, which is lower than that of 1a (vide supra). Previously, we reported that the introduction of electron-donating groups such as methyl and methoxy groups to the pyridine ring of the PNP-pincer ligand in 2 markedly enhanced the catalytic activity under the same reaction conditions ${ }^{41}$.

The time profile of the catalytic reactions using $\mathbf{1 a}$ and $\mathbf{1 c}$ as catalysts was monitored (see Supplementary Methods for the detailed procedure). Typical results are shown in Fig. 6 together with the time profile using $\mathbf{2}$ as a catalyst ${ }^{41,42}$. The turnover frequency (TOF) for ammonia formation, which was determined as mols of ammonia (based on the catalyst) produced in initial $1 \mathrm{~h}$, was $42 \mathrm{~h}^{-1}$ for $1 \mathrm{a}$ and $53 \mathrm{~h}^{-1}$ for $\mathbf{1 c}$. The TOFs for ammonia using $1 \mathrm{a}$ and $1 \mathrm{c}$ are ca. 2.5 and 3.1 times larger than that using 2 $\left(17 \mathrm{~h}^{-1}\right)$, respectively. This result indicates that the dinitrogenbridged dimolybdenum complexes bearing PCP[1]-type pincer ligands such as 1a and 1c have the effective performance not only on the catalytic activity but also on the rate for ammonia formation.

For comparison of the stability of the dinitrogen-bridged dimolybdenum complexes bearing PCP-pincer ligands with that of PNP-pincer ligands, we carried out the following catalytic reactions using $\mathbf{1 a}$ and $\mathbf{2}$ as catalysts. After the formation of 47 equiv. of ammonia based on the catalyst from molecular dinitrogen following the same procedure of the time profile experiment using 1a, the same amounts of [LutH]OTf and $\mathrm{CrCp}_{2}{ }_{2}$ were further added at room temperature, and the mixture was stirred for another $2 \mathrm{~h}$ to afford a total of 69 equiv. of ammonia based on the catalyst (Fig. 7; see Supplementary Methods for the detailed procedure). In this reaction system, 22 equiv. of ammonia were produced from a further reaction of molecular dinitrogen with excess amounts of a proton source and a reductant. This experimental result indicates that the active species derived from 1a remain even after the catalytic reaction. In fact, no free PCP-pincer ligand was observed from the reaction mixture after the catalytic reaction using $\mathbf{1 a}$ as a catalyst, suggesting that the active species derived from 1a were still active. In sharp contrast, no additional ammonia was produced from similar treatment using 2 as a catalyst (Fig. 7), where free PNP-pincer ligand was observed from the reaction mixture after the catalytic reaction using 2 as a catalyst ${ }^{40}$. These results indicate that the stability of $\mathbf{1 a}$ is much improved compared with that of 2 .

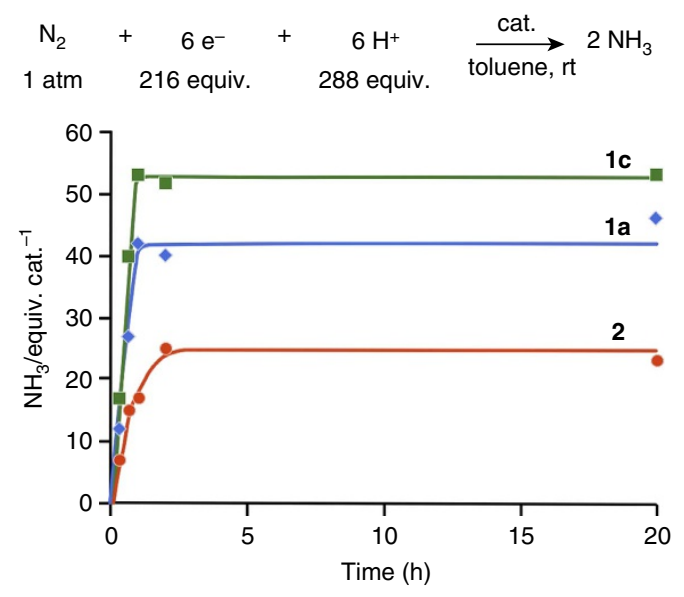

Figure 6 | Time profiles of the formation of ammonia from dinitrogen

gas. A solution of $\mathrm{CrCp}_{2}{ }_{2}(0.72 \mathrm{mmol})$ in toluene was added to a mixture of 1a or 1c $(0.0033 \mathrm{mmol})$ and [ $\mathrm{LutH}] \mathrm{OTf}(0.96 \mathrm{mmol})$ at room temperature over a period of $1 \mathrm{~h}$ under $1 \mathrm{~atm}$ of dinitrogen gas, followed by stirring for the indicated time $(0.33,0.67,1,2$ and $20 \mathrm{~h})$. A solution of $\mathrm{CoCp}_{2}(2.16 \mathrm{mmol})$ in toluene was added to a mixture of $\mathbf{2}(0.010 \mathrm{mmol})$ and [LutH]OTf $(2.88 \mathrm{mmol})$ at room temperature over a period of $1 \mathrm{~h}$ under $1 \mathrm{~atm}$ of dinitrogen gas, followed by stirring for the indicated time $(0.33,0.67,1,2$ and $20 \mathrm{~h}$ ). The amount of ammonia (equiv.) is based on the catalyst.

Comparison of PCP and PNP ligands. In this section, we compare the electronic properties and reactivity of $\mathbf{1 a}$ and $\mathbf{2}$. We have previously reported that the catalytic activity of $\mathbf{2}$ was improved by the introduction of electron-donating groups to the 4-position of the pyridine ring in $\mathrm{PNP}^{41}$. In this report, DFT calculations demonstrated that the introduction of electrondonating groups to PNP enhances the backdonating ability of molybdenum centres and thereby leads to activation of dinitrogen ligands. As described in the Introduction, the NHC-based PCP ligand was expected to work as a strong electron donor to activate dinitrogen ligands coordinated to the molybdenum centre. For understanding the geometric and electronic structures of $\mathbf{1 a}$ and $\mathbf{2}$ upon the coordination of the pincer ligands, mononuclear molybdenum complexes $\mathbf{1} \mathbf{a}^{\prime}$ and $\mathbf{2}^{\prime}$ were investigated in detail.

Figure $8 \mathrm{a}$ compares the electron-donating ability of BimPCP[1] and PNP in terms of differences in atomic charge $(\Delta q)$ between the dinitrogen complexes $\left(\mathbf{1} \mathbf{a}^{\prime}\right.$ and $\left.\mathbf{2}^{\prime}\right)$ and the free ligands (Bim-PCP[1] and PNP). The charges of the Mo atom and three $\mathrm{N}_{2}$ ligands obtained with the natural population analysis (NPA $)^{62}$ were set to zero for the free ligands, and hence the sum of the charges is identical to the $\Delta q$ value of the $\mathrm{Mo}\left(\mathrm{N}_{2}\right)_{3}$ moiety. The gross NPA charges of the $\operatorname{Mo}\left(\mathrm{N}_{2}\right)_{3}$ moiety in $\mathbf{1 a}^{\prime}$ and $\mathbf{2}^{\prime}$ can be regarded as the amount of electron donated from the pincer ligands during complexation. To evaluate the electron-donating ability of Bim-PCP[1] and PNP, the $\Delta q$ values of the $\mathrm{P}^{t} \mathrm{Bu}_{2}$ groups and the carbene or pyridine moiety containing the methylene linkers are separately given in Fig. 8a. The $\Delta q$ values of the $\mathrm{P}^{t} \mathrm{Bu}_{2}$ groups are identical in both Bim-PCP[1] and PNP $(+0.29)$, indicating that the electron-donating ability of BimPCP[1] and PNP is controlled by the carbene and pyridine moieties. Since the $\Delta q$ values of the carbene and pyridine moieties are +0.23 and +0.12 , respectively, the pincer ligands donate $0.81 \mathrm{e}^{-}$(Bim-PNP[1]) and $0.70 \mathrm{e}^{-}$(PNP) to the $\mathrm{Mo}\left(\mathrm{N}_{2}\right)_{3}$ moiety during complexation. As we expected, the NHC-based pincer ligand exhibits a stronger electron-donating ability than the pyridine-based one from a viewpoint of atomic charge.

Optimized structures and BDEs between the molybdenum centre and dinitrogen ligands also reflect the strength of the 


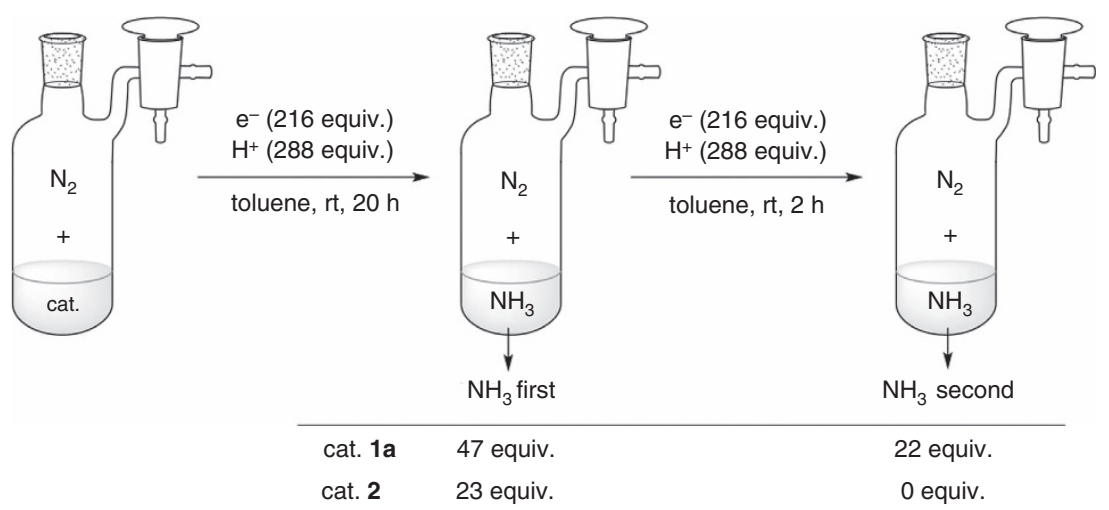

Figure 7 | Reactions of further addition of proton source and reductant. ' $\mathrm{NH}_{3}$ first' and ' $\mathrm{NH}_{3}$ second' were collected in separated runs. Each ' $\mathrm{NH} \mathrm{H}_{3}$ first' is the same value as the time profile experiment. Each ' $\mathrm{NH}_{3}$ second' is collected by the following procedure. A solution of a reductant ( $\mathrm{CrCp}{ }_{2}$ for $\mathbf{1 a}$ and $\mathrm{CoCp} 2$ for $\mathbf{2} ; 216$ equiv) in toluene ( $4 \mathrm{ml})$ was added to a mixture of $\mathbf{1 a}$ or $\mathbf{2}(0.0033 \mathrm{mmol}$ for $\mathbf{1 a}$ and $0.010 \mathrm{mmol}$ for $\mathbf{2})$ and [LutH]OTf (288 equiv) at room temperature over a period of $1 \mathrm{~h}$ under $1 \mathrm{~atm}$ of dinitrogen gas, followed by stirring for $20 \mathrm{~h}$. Then, [LutH]OTf (288 equiv) was added in one portion and another solution of the same reductant ( 216 equiv) in toluene $(4 \mathrm{ml})$ was added over a period of $1 \mathrm{~h}$, followed by stirring at room temperature for another $1 \mathrm{~h}$ under 1 atm of dinitrogen gas. The difference between the amount of ammonia obtained in this experiment and the ' $\mathrm{NH}_{3}$ first' is the ' $\mathrm{NH}_{3}$ second'. The amount of ammonia (equiv.) is based on the catalyst.

electron-donating ability of Bim-PCP[1] and PNP. Table 3 summarizes geometric parameters around the molybdenum centre in mononuclear molybdenum-dinitrogen complexes $\mathbf{1 a}^{\prime}$ and $2^{\prime}$, together with the BDEs of the Mo- $\mathrm{N}_{2}$ (axial) and Mo- $\mathrm{N}_{2}$ (equatorial) bonds. The Mo-C(carbene) bond distance (2.099 $\AA$ ) in $\mathbf{1 a}^{\prime}$ is significantly shorter than the Mo-N(pyridine) distance $(2.240 \AA)$ in $2^{\prime}$. The Mayer bond order (b.o.) ${ }^{63}$ of the Mo-C(carbene) bond is calculated to be 0.91 , which is much larger than that of the Mo-N(pyridine) bond (0.39). The presence of a strong bonding interaction between the molybdenum centre and Bim-PCP $[1]$ is consistent with the experimental fact that 1a bearing Bim-PCP[1] works as a long-lived catalyst for the catalytic nitrogen fixation with a high turnover number compared with 2 bearing PNP (vide supra). On the other hand, the strong trans influence of the carbene ligand weakens the $\mathrm{Mo}-$ $\mathrm{N}_{2}$ (equatorial) bond in $\mathbf{1} \mathbf{a}^{\prime}$. The Mo- $\mathrm{N}_{2}$ (equatorial) bond distance of $2.084 \AA$ (b.o. $=0.50$ ) in $\mathbf{1 a}^{\prime}$ is much longer than that of $2.018 \AA$ (b.o. $=0.62$ ) in $\mathbf{2}^{\prime}$, and the BDEs of the Mo- $\mathrm{N}_{2}$ (equatorial) bond are $21.2 \mathrm{kcal} \mathrm{mol}^{-1}$ for $\mathbf{1 a}^{\prime}$ and $30.1 \mathrm{kcal} \mathrm{mol}^{-1}$ for $\mathbf{2}^{\prime}$. Interestingly, the coordination of Bim$\mathrm{PCP}[1]$ to molybdenum would influence all dinitrogen ligands at both trans- and cis-positions so as to weaken all the $\mathrm{Mo}-\mathrm{N}_{2}$ bonds. The Mo- $\mathrm{N}_{2}$ (axial) bond distances (b.o.) are calculated to be $2.034 \AA(0.53)$ for $\mathbf{1 a}^{\prime}$ and $2.024 \AA(0.54)$ for $\mathbf{2}^{\prime}$. The BDE of the Mo-N $\mathrm{N}_{2}$ (axial) bond of $\mathbf{1 a}^{\prime}\left(12.5 \mathrm{kcal} \mathrm{mol}^{-1}\right)$ is also lower than that of $\mathbf{2}^{\prime}\left(14.0 \mathrm{kcal} \mathrm{mol}^{-1}\right)$. A similar trend was observed for the Mo- $\mathrm{N}_{2}$ (bridging) and $\mathrm{Mo}-\mathrm{N}_{2}$ (terminal) bonds in dimolybdenum-dinitrogen complexes $\mathbf{1 a}$ and 2 . The bond dissociation energies are 18.8 and $11.9 \mathrm{kcal} \mathrm{mol}^{-1}$ for 1a, both of which are smaller than those obtained for 2 (24.9 and $14.4 \mathrm{kcal} \mathrm{mol}^{-1}$ ).

The origin of the weaker $\mathrm{Mo}-\mathrm{N}_{2}$ bonds in $\mathbf{1 a}^{\prime}$ and $\mathbf{1 a}$ is understood by looking at frontier orbitals responsible for the bonding between the molybdenum centre and the carbene $\mathrm{C}$ atom of Bim-PCP $[1]^{52,53,64,65}$. As depicted in Fig. $8 \mathrm{~b}$, the HOMO-6 (1. $\left.\mathbf{a}^{\prime}\right)$ and HOMO-5 $\left(\mathbf{2}^{\prime}\right)$ contribute to a $\sigma$-bond between the Mo atom and the carbene $\mathrm{C}$ atom (or the pyridine $\mathrm{N}$ atom). The large size of the lobe between the Mo and $\mathrm{C}$ atoms indicates that Bim-PCP[1] works as a strong $\sigma$-donor compared to PNP. The HOMO-1 in Fig. $8 \mathrm{c}$ mainly contributes to $\pi$-backdonation from an out-of-plane $d$ orbital of Mo to a $\pi^{*}$ orbital of dinitrogen ligands. The backdonation from metal to dinitrogen is essential for the activation of dinitrogen upon the formation of metal-dinitrogen complexes. Occupation of the HOMO-1 strengthens all of the Mo- $\mathrm{N}_{2}$ bonds in $\mathbf{1 a}^{\prime}$ and $\mathbf{2}^{\prime}$ because of their symmetrical structures. By comparing the HOMO-1 of $1 \mathbf{a}^{\prime}$ and $\mathbf{2}^{\prime}$, one can find a bonding interaction between the Mo atom and the carbene $\mathrm{C}$ atom through $\pi$-backdonation from the $d$ orbital of Mo to the vacant $p$ orbital of $\mathrm{C}$ perpendicular to the carbene ring in $\mathbf{1 \mathbf { a } ^ { \prime }}$. This backdonation decreases the amount of electron transferred to both the equatorial and axial dinitrogen ligands, leading to the lower BDEs of the Mo-N $\mathrm{N}_{2}$ bonds in $\mathbf{1} \mathbf{a}^{\prime}(\mathbf{1 a})$. As presented in Fig. $8 \mathrm{a}$, the $\Delta q$ value of the dinitrogen ligands in $\mathbf{1} \mathbf{a}^{\prime}(-0.26)$ is smaller than that in $2^{\prime}(-0.31)$ in spite of the electron-donating ability of Bim-PCP[1] superior to PNP. The backdonation from the Mo atom to the carbene $\mathrm{C}$ atom also contributes to the strong binding of Bim-PCP[1] to Mo.

On the other hand, the Mo-C bond distance (b.o.) in $\mathbf{1 b}^{\prime}$ bearing Im-PCP[2] (2.178 $\AA$ (0.79)) indicates that the Mo-C bond in $\mathbf{1} \mathbf{b}^{\prime}$ is weaker than that in $\mathbf{1 a}^{\prime}$, as summarized in Table 3. Owing to the longer $\mathrm{CH}_{2}$ linkers, the coordination of the carbene moiety to the molybdenum centre in $\mathbf{1} \mathbf{b}^{\prime}$ is highly twisted compared to $1 \mathbf{a}^{\prime}$; the dihedral angles of $\mathrm{N}(1)-\mathrm{C}(1)-\mathrm{Mo}(1)-\mathrm{N}(3)$ are $69.6^{\circ}$ for $\mathbf{1 a}^{\prime}$ and $43.8^{\circ}$ for $\mathbf{1 b}^{\prime}$ (Supplementary Fig. 21). The twisted coordination of the carbene moiety in $\mathbf{1}^{\prime}$ reduces the overlap between the out-of-plane $d$ orbital of the Mo atom and the vacant $p$ orbital of the carbene $C$ atom. As a result, Im-PCP[2] works only as a very strong $\sigma$-donor $\left(0.90 \mathrm{e}^{-}\right.$donation to $\mathrm{Mo}$; Fig. 8a). The gross NPA charge on the dinitrogen ligands $(-0.36)$ as well as the large BDE of the Mo- $\mathrm{N}_{2}$ (axial) bond of $\mathbf{1} \mathbf{b}^{\prime}$ $\left(14.3 \mathrm{kcal} \mathrm{mol}^{-1}\right)$ implies that the coordination of Im-PCP[2] to the molybdenum centre effectively activates the coordinated dinitrogen ligands. However, we theoretically confirmed that the mononuclear molybdenum-dinitrogen complexes such as $\mathbf{1 b}^{\prime}$ and $\left.\left[\text { cis-Mo( } \mathrm{N}_{2}\right)_{2}(\mathrm{Im}-\mathrm{PCP}[2])\right]$ cannot be protonated by $\mathrm{LutH}^{+}$, similar to $\mathbf{1 a}^{\prime}$ and $\left[\mathrm{Mo}\left(\mathrm{N}_{2}\right)_{3}(\mathrm{PNP})\right]^{43}$. All attempts to optimize a product complex comprise the protonated $\mathbf{1 a}^{\prime}\left(\mathbf{1 b}^{\prime}\right)$, and Lut resulted in formation of a reactant complex comprising $\mathbf{1} \mathbf{a}^{\prime}\left(\mathbf{1 b}^{\prime}\right)$ and $\mathrm{LutH}^{+}$, even though the optimization started from a structure with the $\mathrm{N}_{2} \ldots \mathrm{H}^{+}$distance of $5 \AA$. Thus, the lack of the catalytic activity of $\mathbf{1 b}$ for nitrogen fixation can be attributed to the thermodynamic instability of the dinitrogen-bridged dimolybdenum structure, as mentioned in the former section.

On the basis of the catalytic reaction pathway previously proposed for nitrogen fixation using 2 (ref. 43), we have 
a

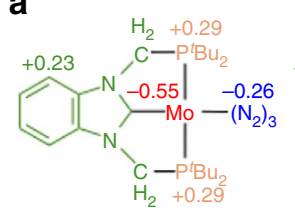

$1 a^{\prime}$

b

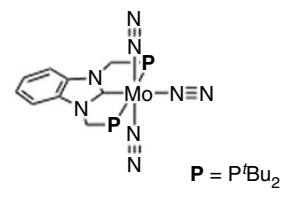

$\left[\mathrm{Mo}\left(\mathrm{N}_{2}\right)_{3}(\mathrm{Bim}-\mathrm{PCP}[1])\left(\mathbf{1 a}^{\prime}\right)\right.$

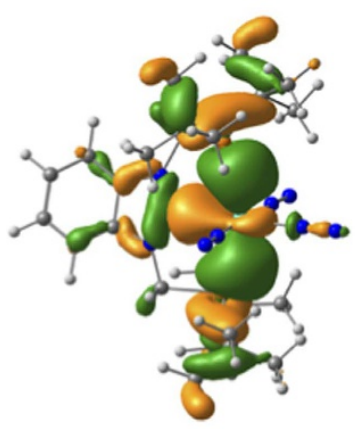

HOMO-6 (1a')

C

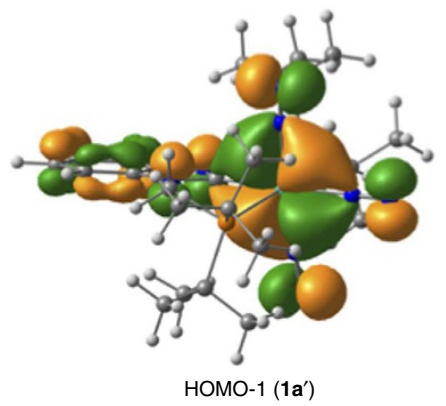

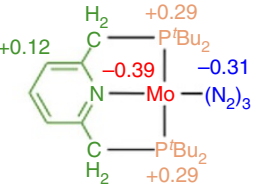

$\mathbf{2}^{\prime}$

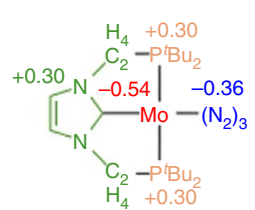

$1 b^{\prime}$

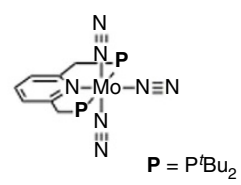

$\left[\mathrm{Mo}\left(\mathrm{N}_{2}\right)_{3}(\mathrm{PNP})\right]\left(\mathbf{2}^{\prime}\right)$

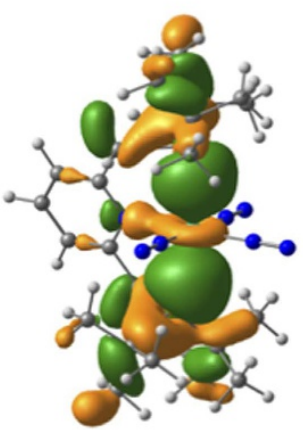

HOMO-5 (2')

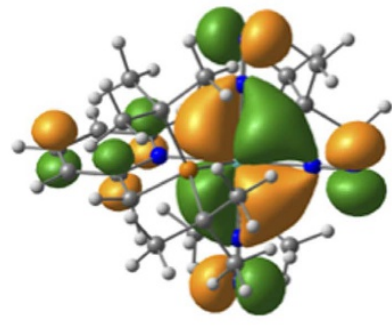

HOMO-1 (2') d
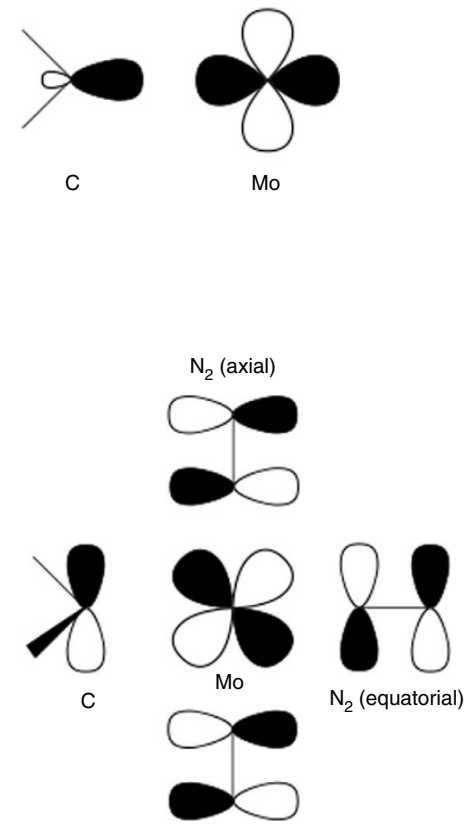

$\mathrm{N}_{2}$ (axial)

Figure 8 | Electronic properties of mononuclear molybdenum-dinitrogen complexes. (a) Changes in the NPA atomic charge ( $\Delta q)$ in the coordination of the pincer ligands to the $\mathrm{Mo}\left(\mathrm{N}_{2}\right)_{3}$ moiety. The values of $\Delta q$ are obtained as differences between mononuclear Mo- $\mathrm{N}_{2}$ complexes $\left(\mathbf{1}^{\prime}, \mathbf{2}^{\prime}\right.$ and $\left.\mathbf{1 b}^{\prime}\right)$ and free ligands (Bim-PCP[1] for $\mathbf{1} \mathbf{a}^{\prime}$, PNP for $\mathbf{2}^{\prime}$ and Im-PCP[2] for $\mathbf{1 b}^{\prime}$ ). (b) Spatial distribution of frontier orbitals of $\mathbf{1} \mathbf{a}^{\prime}$ and $\mathbf{2}^{\prime}$ that contribute to $\sigma$ donation from the pincer ligand to Mo. (c) Spatial distribution of frontier orbitals of $\mathbf{1} \mathbf{a}^{\prime}$ and $\mathbf{2}^{\prime}$ that contribute to $\pi$ back donation from Mo to both equatorial and axial dinitrogen ligands. The molecular structures are rotated by $90^{\circ}$ along the Mo- $\mathrm{N}_{2}$ (equatorial) bond from those in Fig. 8 b. (d) A schematic drawing of the bonding interactions between the Mo atom and the carbene $C$ atom in $\mathbf{1} \mathbf{a}^{\prime}$.

theoretically investigated possible reaction pathways catalysed by 1a. In the present article, we particularly focus on the first protonation process shown in Fig. 9, since the protonation of a terminal dinitrogen ligand in $\mathbf{2}$ by [LutH]OTf is energetically the most unfavourable process in the catalytic cycle ${ }^{43}$. In the calculated reaction pathway, a terminal dinitrogen ligand in 1a is first protonated by $\mathrm{LutH}^{+}(\mathbf{1} \mathbf{a} \rightarrow \mathbf{A}-\mathrm{PCP})$, and then the dinitrogen ligand trans to the generated $\mathrm{NNH}$ group is eliminated $(\mathbf{A}-\mathrm{PCP} \rightarrow \mathbf{B}-\mathrm{PCP})$. The protonation of $\mathbf{1 a}$ yielding $\mathbf{A}-\mathrm{PCP}$ is endothermic by $8.1 \mathrm{kcal} \mathrm{mol}^{-1}$ with an activation energy of $8.3 \mathrm{kcal} \mathrm{mol}^{-1}$. This energy profile indicates that proton detachment from A-PCP can easily occur like the PNP system. On the other hand, the following $\mathrm{N}_{2}$ elimination yielding B-PCP is exothermic by $5.2 \mathrm{kcal} \mathrm{mol}^{-1}$ with a low activation energy of $4.0 \mathrm{kcal} \mathrm{mol}^{-1}$. The coordination of OTf ${ }^{-}$to B-PCP is highly exothermic by $20.7 \mathrm{kcal} \mathrm{mol}^{-1}$, and thus the whole reaction pathway leading to C-PCP is energetically downhill. Comparison of the energy profiles of the PCP and PNP systems suggests that the reactivity of the dinitrogen complexes $\mathbf{1 a}$ and $\mathbf{2}$ with [LutH]OTf would not be a major factor for rationalizing the high catalytic activity of 1a.

\section{Discussion}

On the basis of our previous findings on the catalytic nitrogen fixation, we have newly designed and prepared novel dinitrogenbridged dimolybdenum complexes bearing NHC and phosphinebased PCP-pincer ligands, Bim-PCP[1] and Im-PCP[2]. The dimolybdenum-dinitrogen complexes bearing Bim-PCP [1] as PCP-pincer ligands have been found to work as so far the most effective catalysts towards the ammonia formation from 
Table 3 | Selected bond distances in $\AA$ and $\mathrm{Mo}-\mathrm{N}_{2}$ BDEs in $\mathrm{kcal} \mathrm{mol}^{-1}$ of mononuclear molybdenum-dinitrogen complexes.

\begin{tabular}{lccc} 
& $\mathbf{1 a}^{\prime}$ & $\mathbf{2}^{\prime}$ & $\mathbf{1 b}^{\prime}$ \\
\hline Mo-C(carbene)/N(pyridine) & $2.099(0.91)$ & $2.240(0.39)$ & $2.178(0.79)$ \\
Mo-N(equatorial) & $2.084(0.50)$ & $2.018(0.62)$ & $2.041(0.55)$ \\
Mo-N(axial) & $2.034(0.53)$ & $2.024(0.54)$ & $2.026(0.53)$ \\
BDE $\left(\right.$ equatorial $\left.N_{2}\right)$ & 21.2 & 30.1 & 21.5 \\
BDE $\left(\right.$ axial $\left.N_{2}\right)$ & 12.5 & 14.0 & 14.3 \\
\hline
\end{tabular}

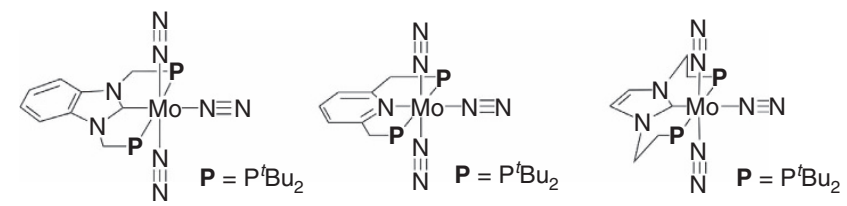

$\left[\mathrm{Mo}\left(\mathrm{N}_{2}\right)_{3}(\mathrm{Bim}-\mathrm{PCP}[1])\right]\left(\mathbf{1} \mathbf{a}^{\prime}\right) \quad\left[\mathrm{Mo}\left(\mathrm{N}_{2}\right)_{3}(\mathrm{PNP})\right]\left(\mathbf{2}^{\prime}\right) \quad\left[\mathrm{Mo}\left(\mathrm{N}_{2}\right)_{3}(\mathrm{Im}-\mathrm{PCP}[2])\right]\left(\mathbf{1 b}^{\prime}\right)$

$\mathrm{BDE}$, bond dissociation energy.

The Mayer bond orders are presented in parenthesis.
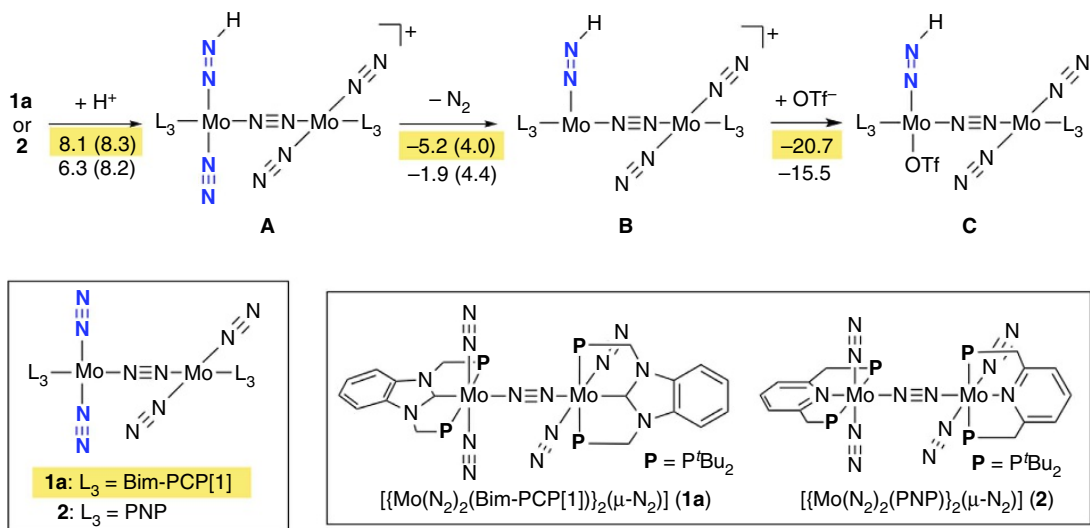

Figure 9 | A possible reaction pathway and energy profiles of the first protonation process on a terminal dinitrogen ligand in 1a (highlighted in yellow) and 2. Energy changes (activation energies in parentheses) are presented in $\mathrm{kcal} \mathrm{mol}^{-1}$.

molecular dinitrogen under ambient reaction conditions, where up to 230 equiv. of ammonia were produced based on the catalyst (115 equiv. of ammonia based on the molybdenum atom of the catalyst). The superior activity of dimolybdenum-dinitrogen complexes bearing Bim-PCP[1] included the high TOF for ammonia formation and the catalyst stability. DFT calculations on 1 reveal that Bim-PCP[1] as a PCP-pincer ligand serves as not only a strong $\sigma$-donor but also a $\pi$-acceptor. These electronic properties are responsible for a solid connection between the molybdenum centre and the pincer ligand, leading to the enhanced catalytic activity for nitrogen fixation.

\section{Methods}

General information. Detailed experimental procedures, characterization of compounds and the computational details can be found in the Supplementary Figs 1-21, Supplementary Tables 1-10 and Supplementary Methods. Cartesian coordinates are available in Supplementary Data 1.

Synthesis of $\left[\mathrm{MoCl}_{\mathbf{3}}(\mathbf{P C P})\right](\mathbf{3 a - 3 c})$. A typical procedure for the preparation of $3 \mathbf{a}$ is described below. To a mixed solid of 1,3-bis((di-tert-butylphosphino)methyl)$1 \mathrm{H}$-benzo[d]imidazol-3-ium hexafluorophosphate $(7 \mathrm{a}, 1.16 \mathrm{~g}, 2.00 \mathrm{mmol})$ and $\mathrm{KN}\left(\mathrm{SiMe}_{3}\right)_{2}(559 \mathrm{mg}, 2.80 \mathrm{mmol})$ was added toluene $(40 \mathrm{ml})$, and the resulting suspension was stirred for $20 \mathrm{~min}$ at room temperature. $\left[\mathrm{MoCl}_{3}(\mathrm{thf})_{3}\right](733 \mathrm{mg}$, $1.75 \mathrm{mmol})$ and toluene $(15 \mathrm{ml})$ were added to the suspension and stirred at $80^{\circ} \mathrm{C}$ for $19 \mathrm{~h}$. The solvent was removed under vacuum, and the residue was washed with hexane $(5 \mathrm{ml} \times 2)$, toluene $(10 \mathrm{ml})$ and hexane $(5 \mathrm{ml} \times 2)$. The solid was dried under vacuum. The solid was extracted with $\mathrm{CH}_{2} \mathrm{Cl}_{2}(10 \mathrm{ml} \times 1,5 \mathrm{ml} \times 7)$ recrystallized from $\mathrm{CH}_{2} \mathrm{Cl}_{2}$-hexane and dried under vacuum to afford $3 \mathrm{a} \cdot 0.5 \mathrm{CH}_{2} \mathrm{Cl}_{2}(712 \mathrm{mg}, 1.05 \mathrm{mmol}, 60 \%)$. Anal. Calcd. for $\mathrm{C}_{25.5} \mathrm{H}_{45} \mathrm{Cl}_{4} \mathrm{MoN}_{2} \mathrm{P}_{2}$ $\left(3 \mathbf{a} \cdot 0.5 \mathrm{CH}_{2} \mathrm{Cl}_{2}\right)$ : C, 45.08; H, 6.68; N, 4.12. Found: C, 45.41; H, 6.61; N, 4.44. Crystals suitable for preliminary $\mathrm{X}$-ray analysis were prepared by recrystallizing from $\mathrm{CH}_{2} \mathrm{Cl}_{2}$-hexane to give $3 \mathbf{a} \cdot \mathrm{CH}_{2} \mathrm{Cl}_{2}$ as orange-brown crystals.

3b: Recrystallization from $\mathrm{CH}_{2} \mathrm{Cl}_{2}$-hexane gave $\mathbf{3 b} \cdot 0.5 \mathrm{CH}_{2} \mathrm{Cl}_{2}$ as orange crystals. $33 \%$ yield. Anal. Calcd. for $\mathrm{C}_{23.5} \mathrm{H}_{47} \mathrm{Cl}_{4} \mathrm{MoN}_{2} \mathrm{P}_{2}\left(3 \mathbf{b} \cdot 0.5 \mathrm{CH}_{2} \mathrm{Cl}_{2}\right): \mathrm{C}, 42.94$; H, 7.21; N, 4.26. Found: C, 43.04; H, 7.44; N, 4.19. Crystals suitable for X-ray analysis were prepared by recrystallizing from 1,2-dichloroethane-hexane to afford 3b $\cdot 1 / 3 \mathrm{C}_{6} \mathrm{H}_{14}$. The structure is included in Supplementary Fig. 2 and selected bond lengths and angles in $\mathbf{3 b}$ are included in Supplementary Table 6.

3c: Recrystallization from $\mathrm{CH}_{2} \mathrm{Cl}_{2}$-hexane afforded $3 \mathrm{c} \cdot 0.5 \mathrm{CH}_{2} \mathrm{Cl}_{2}$ as orange crystals. $48 \%$ yield. Anal. Calcd. for $\mathrm{C}_{27.5} \mathrm{H}_{49} \mathrm{Cl}_{4} \mathrm{MoN}_{2} \mathrm{P}_{2}\left(3 \mathrm{c} \cdot 0.5 \mathrm{CH}_{2} \mathrm{Cl}_{2}\right): \mathrm{C}, 46.69$; $\mathrm{H}, 6.98 ; \mathrm{N}, 3.96$. Found: $\mathrm{C}, 46.58 ; \mathrm{H}, 6.79 ; \mathrm{N}, 4.07$. The structure is included in Supplementary Fig. 3, and selected bond lengths and angles in $3 \mathrm{c}$ are included in Supplementary Table 7.

Synthesis of $\left[\left\{\mathbf{M o}\left(\mathbf{N}_{\mathbf{2}}\right)_{\mathbf{2}}(\mathbf{P C P})\right\}_{\mathbf{2}}\left(\boldsymbol{\mu}-\mathbf{N}_{\mathbf{2}}\right)\right]$ (1a-1c). A typical procedure for the preparation of $\mathbf{1 a}$ is described below. To a suspension of $\mathrm{Na}-\mathrm{Hg}(0.5 \mathrm{wt} \% \mathrm{Na}, 13.8 \mathrm{~g}$, $3.00 \mathrm{mmol})$ in THF was added $\left[\mathrm{MoCl}_{3}(\mathrm{Bim}-\mathrm{PCP}[1])\right] \cdot 0.5 \mathrm{CH}_{2} \mathrm{Cl}_{2}(341 \mathrm{mg}$, $0.501 \mathrm{mmol}$ ), and the resulting suspension was stirred under atmospheric pressure of $\mathrm{N}_{2}$ at room temperature for $17 \mathrm{~h}$. The supernatant suspension was filtered through Celite, and the solvent was removed under vacuum. The resulting solid was extracted with benzene $(5 \mathrm{ml})$ and filtered through Celite. The filter cake was washed with benzene $(2 \mathrm{ml} \times 9)$, and the solvent of the combined solution was removed under vacuum. The resulting solid was washed with pentane $(2 \mathrm{ml} \times 20)$ to give

1a $\cdot 1.3 \mathrm{C}_{4} \mathrm{H}_{8} \mathrm{O} \cdot 0.4 \mathrm{C}_{5} \mathrm{H}_{12}$ as a dark purple solid, where 1.3 equiv. of THF and 0.4 equiv. of hexane were determined by ${ }^{1} \mathrm{H}$ NMR (141 mg, $\left.0.102 \mathrm{mmol}, 37 \%\right)$. Analytically pure sample was prepared by recrystallization from THF at $-18{ }^{\circ} \mathrm{C}$ to afford 1 a.

1a: ${ }^{1} \mathrm{H}$ NMR $\left(\mathrm{C}_{6} \mathrm{D}_{6}\right): \delta 7.01-6.98(\mathrm{~m}, 4 \mathrm{H}, \mathrm{ArH}), 6.75-6.71(\mathrm{~m}, 4 \mathrm{H}, \mathrm{ArH}), 3.84$ $\left(\mathrm{s}, 8 \mathrm{H}, \mathrm{NCH}_{2} \mathrm{P}\right.$ ), 1.38 (pseudo t, $\left.{ }^{3} J_{\mathrm{P}-\mathrm{H}}=5.7 \mathrm{~Hz}, 72 \mathrm{H}, \mathrm{P}^{t} \mathrm{Bu}_{2}\right) .{ }^{31} \mathrm{P}\left\{{ }^{1} \mathrm{H}\right\} \mathrm{NMR}\left(\mathrm{C}_{6} \mathrm{D}_{6}\right)$ : $105.6\left(\mathrm{~s}, P^{t} \mathrm{Bu}_{2}\right)$. Infrared $\left(\mathrm{KBr}, \mathrm{cm}^{-1}\right): 1,978\left(\mathrm{~s}, v_{\mathrm{NN}}\right)$. Infrared $\left(\mathrm{THF}, \mathrm{cm}^{-1}\right)$ : $1,979\left(\mathrm{~s}, v_{\mathrm{NN}}\right)$. Anal. Calcd. for $\mathrm{C}_{50} \mathrm{H}_{88} \mathrm{Mo}_{2} \mathrm{~N}_{14} \mathrm{P}_{4}$ : C, 50.00; $\mathrm{H}, 7.38$;

$\mathrm{N}, 16.33$. Found: $\mathrm{C}, 49.66 ; \mathrm{H}, 6.94 ; \mathrm{N}, 14.18$. The lower content of nitrogen is 
considered to be due to the labile property of the coordinated dinitrogen ligand in 1a under the analytical conditions.

1b: Recrystallization from benzene-hexane afforded $\mathbf{1 b} \cdot 2 / 3 \mathrm{C}_{6} \mathrm{H}_{14}$ as dark-brown crystals. $53 \%$ yield. Anal. Calcd. for $\mathrm{C}_{50} \mathrm{H}_{101.33} \mathrm{Mo}_{2} \mathrm{~N}_{14} \mathrm{P}_{4}\left(\mathbf{l b} \cdot 2 / 3 \mathrm{C}_{6} \mathrm{H}_{14}\right): \mathrm{C}, 49.44 ; \mathrm{H}$, 8.41; N, 16.14. Found: $\mathrm{C}, 49.82 ; \mathrm{H}, 8.40 ; \mathrm{N}, 15.35 .{ }^{1} \mathrm{H}$ and ${ }^{31} \mathrm{P}\left\{{ }^{1} \mathrm{H}\right\}$ NMR were measured in THF- $d_{8}$ as a mixture of $\mathbf{1 b}$ and $\mathbf{1} \mathbf{b}^{\prime} .{ }^{1} \mathrm{H}$ NMR (THF- $\left.d_{8}\right)$ : $\mathbf{1 b}, \delta 6.76(\mathrm{~s}, 2 \mathrm{H}$, $\mathrm{NCHCHN}$ ), 1.44 (pseudo t, ${ }^{3} \mathrm{~J}_{\mathrm{P}-\mathrm{H}}=11.2 \mathrm{~Hz}, \mathrm{P}^{t} B u_{2}$ ), 0.95 (pseudo t, ${ }^{3} J_{\mathrm{P}-\mathrm{H}}=11.2 \mathrm{~Hz}$, $\left.\mathrm{P}^{t} B u_{2}\right): 1 \mathbf{b}^{\prime}, \delta 6.85$ (s, 2H, NCHCHN), 4.29-4.19 (br m, 4H, NCH $), 1.98-1.91$ (br m, $4 \mathrm{H}, \mathrm{CH}_{2} \mathrm{P}$ ), 1.18 (br s, $\left.36 \mathrm{H}, \mathrm{P}^{t} B u_{2}\right) .{ }^{31} \mathrm{P}\left\{{ }^{1} \mathrm{H}\right\}$ NMR (THF- $\left.d_{8}\right): \mathbf{1 b}, \delta 71.1\left(\mathrm{~s},{ }^{t} \mathrm{Bu}_{2} P\right): \mathbf{1 b}^{\prime}$, $\delta 69.2\left(\mathrm{~s},{ }^{t} \mathrm{Bu}_{2} P\right)$. Infrared $\left(\mathrm{KBr}, \mathrm{cm}^{-1}\right): 1,911\left(\mathrm{~s}, v_{\mathrm{NN}}\right.$ for $\left.\mathbf{l b}\right)$. Infrared (THF under $\mathrm{N}_{2}$, $\left.\mathrm{cm}^{-1}\right): 2,041\left(\mathrm{~m}, v_{\mathrm{NN}}\right.$ for $\left.\mathbf{l b}^{\prime}\right), 1,945\left(\mathrm{~s}, v_{\mathrm{NN}}\right.$ for $\left.\mathbf{1 b}^{\prime}\right)$

1c: Reprecipitation from THF-hexane afforded $\mathbf{1 c} \cdot 0.5 \mathrm{C}_{6} \mathrm{H}_{14}$ as a brown solid. $46 \%$ yield. Crystals suitable for X-ray analysis were prepared by recrystallization from THF at $-18^{\circ} \mathrm{C}$ to afford $\mathbf{1 c}$. The structure is included in Supplementary Fig. 1, and selected bond lengths and angles are included in Supplementary Table 5. ${ }^{1} \mathrm{H}$ NMR $\left(\mathrm{C}_{6} \mathrm{D}_{6}\right): \delta 6.68(\mathrm{~s}, 4 \mathrm{H}, \mathrm{ArH}), 3.89\left(\mathrm{~s}, 8 \mathrm{H}, \mathrm{NCH}_{2} \mathrm{P}\right), 2.26\left(\mathrm{~s}, 12 \mathrm{H}, \mathrm{ArCH}_{3}\right)$, 1.41 (pseudo t, $\left.{ }^{3} J_{\mathrm{P}-\mathrm{H}}=5.5 \mathrm{~Hz}, 72 \mathrm{H}, \mathrm{P}^{t} B u_{2}\right) .{ }^{31} \mathrm{P}\left\{{ }^{1} \mathrm{H}\right\}$ NMR $\left(\mathrm{C}_{6} \mathrm{D}_{6}\right): \delta 105.8$ $\left(\mathrm{s}, P^{t} \mathrm{Bu}_{2}\right)$. Infrared $\left(\mathrm{KBr}, \mathrm{cm}^{-1}\right): 1,969\left(\mathrm{~s}, v_{\mathrm{NN}}\right)$. Infrared (THF, $\left.\mathrm{cm}^{-1}\right): 1,973$ (s, $\left.v_{\mathrm{NN}}\right)$. Anal. Calcd. for $\mathrm{C}_{57} \mathrm{H}_{103} \mathrm{Mo}_{2} \mathrm{~N}_{14} \mathrm{P}_{4}\left(1 \mathrm{c} \cdot 0.5 \mathrm{C}_{6} \mathrm{H}_{14}\right)$ : C, 52.65; H, 7.98; N, 15.08. Found: C, 52.80; H, 7.70; N, 13.37 .

Catalytic reduction of dinitrogen to ammonia under $\mathbf{N}_{\mathbf{2}}$. In a $50 \mathrm{ml}$ Schlenk flask were placed $\mathbf{1 a} \cdot 1.3 \mathrm{C}_{4} \mathrm{H}_{8} \mathrm{O} \cdot 0.4 \mathrm{C}_{5} \mathrm{H}_{12}(12.9 \mathrm{mg}, 0.00970 \mathrm{mmol})$ and 2,6-lutidinium trifluoromethanesulfonate [LutH]OTf $(247 \mathrm{mg}, 0.960 \mathrm{mmol})$. Toluene $(1.0 \mathrm{ml})$ was added under $\mathrm{N}_{2}(1 \mathrm{~atm})$, and then a solution of $\mathrm{CrCp}_{2}^{*}(232 \mathrm{mg}, 0.719 \mathrm{mmol})$ in toluene $(4.0 \mathrm{ml})$ was added to the stirred suspension in the Schlenk flask with a syringe pump at a rate of $4.0 \mathrm{ml} \mathrm{h}^{-1}$. After the addition of $\mathrm{CrCp}_{2}^{*}$, the mixture was further stirred at room temperature for $19 \mathrm{~h}$. The reaction mixture was evaporated under reduced pressure, and the distillate was trapped in dilute $\mathrm{H}_{2} \mathrm{SO}_{4}$ solution $(0.5 \mathrm{M}, 10.00 \mathrm{ml})$. Aqueous solution of potassium hydroxide $(30 \mathrm{wt} \% ; 5 \mathrm{ml})$ was added to the residue to fully liberate ammonia, and the mixture was distilled into another dilute $\mathrm{H}_{2} \mathrm{SO}_{4}$ solution $(0.5 \mathrm{M}, 10.00 \mathrm{ml})$. The amount of $\mathrm{NH}_{3}$ present in each of the $\mathrm{H}_{2} \mathrm{SO}_{4}$ solutions was determined by the indophenol method. ${ }^{61}$

Computational method. DFT calculations were performed to search all intermediates and transition structures on potential energy surfaces using the Gaussian 09 programme ${ }^{66}$. Similar to the previous study ${ }^{43}$, we adopted the B3LYP ${ }^{*}$ functional, which is a reparametrized version of the B3LYP hybrid functional developed by Reiher et al. ${ }^{67}$. For optimization, the Stuttgart-Dresden pseudopotentials and $6-31 \mathrm{G}(\mathrm{d})$ basis sets were chosen for the Mo atom and the other atoms, respectively. To determine the energy profile of the first protonation process, we performed single-point energy calculations at the optimized geometries using the $6-311+\mathrm{G}(\mathrm{d}, \mathrm{p})$ basis sets in place of the $6-31 \mathrm{G}(\mathrm{d})$ basis sets. Zero-point energy corrections were applied for energy changes $(\Delta E)$ and activation energies $\left(E_{\mathrm{a}}\right)$ calculated for each reaction step. Solvation effects (toluene) were taken into account by using the polarizable continuum model in the single-point energy calculations ${ }^{68}$. More details are described in Supplementary Methods. Throughout the paper, the $\mathrm{BDE}$ of an $\mathrm{Mo}-\mathrm{N}_{2}$ (terminal, axial or equatorial) bond is defined as the energy change for dissociation of the corresponding dative $\mathrm{N}_{2}$ ligand, for example, $\left[\left\{\mathrm{Mo}\left(\mathrm{N}_{2}\right)_{2}(\mathrm{PNP})\right\}_{2}\left(\mu-\mathrm{N}_{2}\right)\right] \rightarrow\left[\left\{\mathrm{Mo}\left(\mathrm{N}_{2}\right)(\mathrm{PNP})\right\}-\mathrm{NN}-\left\{\mathrm{Mo}\left(\mathrm{N}_{2}\right)_{2}(\mathrm{PNP})\right\}\right]+\mathrm{N}_{2}$. The $\mathrm{BDE}$ of the Mo- $\mathrm{N}_{2}$ (bridging) bond is defined as the energy change for separation of a dimolybdenum complex into two mononuclear Mo- $\mathrm{N}_{2}$ complexes, such as $\left[\left\{\mathrm{Mo}\left(\mathrm{N}_{2}\right)_{2}(\mathrm{PNP})\right\}_{2}\left(\mu-\mathrm{N}_{2}\right)\right] \rightarrow\left[\mathrm{Mo}\left(\mathrm{N}_{2}\right)_{3}(\mathrm{PNP})\right]+$ cis- $\left[\mathrm{Mo}\left(\mathrm{N}_{2}\right)_{2}(\mathrm{PNP})\right]$.

Data availability. The X-ray crystallographic coordinates for structures reported in this article have been deposited at the Cambridge Crystallographic Data Centre (CCDC), under deposition number CCDC 1482254 (1a), 1482255 (1b), 1482256 (1c), 1482258 (3b) and 1482259 (3c). These data can be obtained free of charge from The Cambridge Crystallographic Data Centre via www.ccdc.cam.ac.uk/ data_request/cif. All other data are available from the authors upon reasonable request.

\section{References}

1. Liu, H. Ammonia Synthesis Catalysts: Innovation and Practice (World Scientific, 2013)

2. Eady, R. R. Current status of structure function relationships of vanadium nitrogenase. Coord. Chem. Rev. 237, 23-30 (2003).

3. Spatzal, T. et al. Evidence for interstitial carbon in nitrogenase FeMo cofactor. Science 334, 940 (2011).

4. Lancaster, K. M. et al. X-ray emission spectroscopy evidences a central carbon in the nitrogenase iron-molybdenum cofactor. Science 334, 974-977 (2011).

5. Wiig, J. A., Hu, Y., Lee, C. C. \& Ribbe, M. W. Radical SAM-dependent carbon insertion into the nitrogenase M-cluster. Science 337, 1672-1675 (2012).

6. Hoffman, B. M., Lukoyanov, D., Yang, Z.-Y., Dean, D. R. \& Seefeldt, L. C. Mechanism of nitrogen fixation by nitrogenase: the next stage. Chem. Rev. 114, 4041-4062 (2014).

7. Hidai, M. \& Mizobe, Y. Recent advances in the chemistry of dinitrogen complexes. Chem. Rev. 95, 1115-1133 (1995).
8. MacKay, B. A. \& Fryzuk, M. D. Dinitrogen coordination chemistry: on the biomimetic borderlands. Chem. Rev. 104, 385-402 (2004).

9. Khoenkhoen, N., de Bruin, B., Reek, J. N. H. \& Dzik, W. I. Reactivity of dinitrogen bound to mid- and late-transition-metal centers. Eur. J. Inorg. Chem. 2015, 567-598 (2015).

10. Nishibayashi, Y. Recent progress in transition-metal-catalyzed reduction of molecular dinitrogen under ambient reaction conditions. Inorg. Chem. 54, 9234-9247 (2015).

11. Tanaka, H., Nishibayashi, Y. \& Yoshizawa, K. Interplay between theory and experiment for ammonia synthesis catalyzed by transition metal complexes. Acc. Chem. Res. 49, 987-995 (2016).

12. Čorić, I., Mercado, B. Q., Bill, E., Vinyard, D. J. \& Holland, P. L. Binding of dinitrogen to an iron-sulfur-carbon site. Nature 526, 96-99 (2015).

13. McSkimming, A. \& Harman, W. H. A terminal $\mathrm{N}_{2}$ complex of high-spin iron(I) in a weak, trigonal ligand field. J. Am. Chem. Soc. 137, 8940-8943 (2015).

14. Lee, Y. et al. Dinitrogen activation upon reduction of a triiron(II) complex. Angew. Chem. Int. Ed. 54, 1499-1503 (2015).

15. Keane, A. J., Farrell, W. S., Yonke, B. L., Zavalij, P. Y. \& Sita, L. R. Metalmediated production of isocyanates, $\mathrm{R}_{3} \mathrm{EN}=\mathrm{C}=\mathrm{O}$ from dinitrogen, carbon dioxide, and $\mathrm{R}_{3} \mathrm{ECl}$. Angew. Chem. Int. Ed. 54, 10220-10224 (2015).

16. Klopsch, I., Kinauer, M., Finger, M., Würtele, C. \& Schneider, S. Conversion of dinitrogen into acetonitrile under ambient conditions. Angew. Chem. Int. Ed. 55, 4786-4789 (2016).

17. Bazhenova, T. A. \& Shilov, A. E. Nitrogen fixation in solution. Coord. Chem. Rev. 144, 69-145 (1995).

18. Shilov, A. E. Catalytic reduction of molecular nitrogen in solutions. Russ. Chem. Bull. 52, 2555-2562 (2003).

19. Shiina, K. Reductive silylation of molecular nitrogen via fixation to tris(trialkylsilyl)amine. J. Am. Chem. Soc. 94, 9266-9267 (1972).

20. Komori, K., Oshita, H., Mizobe, Y. \& Hidai, M. Preparation and properties of molybdenum and tungsten dinitrogen complexes. 25. Catalytic conversion of molecular nitrogen into silylamines using molybdenum and tungsten dinitrogen complexes. J. Am. Chem. Soc. 111, 1939-1940 (1989).

21. Mori, M. Activation of nitrogen for organic synthesis. J. Organomet. Chem. 689, 4210-4227 (2004).

22. Tanaka, H. et al. Molybdenum-catalyzed transformation of molecular dinitrogen into silylamine: experimental and DFT study on the remarkable role of ferrocenyldiphosphine ligands. J. Am. Chem. Soc. 133, 3498-3506 (2011).

23. Liao, Q., Saffon-Merceron, N. \& Mézailles, N. Catalytic dinitrogen reduction at the molybdenum center promoted by a bulky tetradentate phosphine ligand. Angew. Chem. Int. Ed. 53, 14206-14210 (2014).

24. Siedschlag, R. B. et al. Catalytic silylation of dinitrogen with a dicobalt complex. J. Am. Chem. Soc. 137, 4638-4641 (2015).

25. Imayoshi, R. et al. Cobalt-catalyzed transformation of molecular dinitrogen into silylamine under ambient reaction conditions. Chem. Eur. J. 21, 8905-8909 (2015).

26. Liao, Q., Saffon-Merceron, N. \& Mézailles, N. $\mathrm{N}_{2}$ reduction into silylamine at tridentate phosphine/Mo center: catalysis and mechanistic study. ACS Catal 5, 6902-6906 (2015).

27. Kuriyama, S. et al. Catalytic transformation of dinitrogen into ammonia and hydrazine by iron-dinitrogen complexes bearing pincer ligand. Nat. Commun. 7, 12181 (2016).

28. Kuriyama, S. et al. Direct transformation of molecular dinitrogen into ammonia catalyzed by cobalt dinitrogen complexes bearing anionic PNP pincer ligands. Angew. Chem. Int. Ed. 55, 14291-14295 (2016).

29. Yandulov, D. V. \& Schrock, R. R. Catalytic reduction of dinitrogen to ammonia at a single molybdenum center. Science 301, 76-78 (2003).

30. Ritleng, V. et al. Molybdenum triamidoamine complexes that contain hexatert-butylterphenyl, hexamethylterphenyl, or p-bromohexaisopropylterphenyl substituents. An examination of some catalyst variations for the catalytic reduction of dinitrogen. J. Am. Chem. Soc. 126, 6150-6163 (2004).

31. Schrock, R. R. Catalytic reduction of dinitrogen to ammonia at a single molybdenum center. Acc. Chem. Res. 38, 955-962 (2005).

32. Schrock, R. R. Catalytic reduction of dinitrogen to ammonia by molybdenum: theory versus experiment. Angew. Chem. Int. Ed. 47, 5512-5522 (2008).

33. Anderson, J. S., Rittle, J. \& Peters, J. C. Catalytic conversion of nitrogen to ammonia by an iron model complex. Nature 501, 84-87 (2013).

34. Creutz, S. E. \& Peters, J. C. Catalytic reduction of $\mathrm{N}_{2}$ to $\mathrm{NH}_{3}$ by an Fe- $\mathrm{N}_{2}$ complex featuring a C-atom anchor. J. Am. Chem. Soc. 136, 1105-1115 (2014)

35. Ung, G. \& Peters, J. C. Low-temperature $\mathrm{N}_{2}$ binding to two-coordinate $\mathrm{L}_{2} \mathrm{Fe}^{0}$ enables reductive trapping of $\mathrm{L}_{2} \mathrm{FeN}_{2}^{-}$and $\mathrm{NH}_{3}$ generation. Angew. Chem. Int. Ed. 54, 532-535 (2015).

36. Rittle, J. \& Peters, J. C. Fe- $\mathrm{N}_{2} / \mathrm{CO}$ complexes that model a possible role for the interstitial $\mathrm{C}$ atom of FeMo-cofactor (FeMoco). Proc. Natl Acad. Sci. USA 110 , 15898-15903 (2013).

37. Rittle, J., McCrory, C. C. L. \& Peters, J. C. A $10^{6}$-fold enhancement in $\mathrm{N}_{2}$ binding affinity of an $\mathrm{Fe}_{2}(\mu-\mathrm{H})_{2}$ core upon reduction to a mixed-valence $\mathrm{Fe}^{\mathrm{II}} \mathrm{Fe}^{\mathrm{I}}$ state. J. Am. Chem. Soc. 136, 13853-13862 (2014). 
38. Rittle, J. \& Peters, J. C. An Fe- $\mathrm{N}_{2}$ complex that generates hydrazine and ammonia via $\mathrm{Fe}=\mathrm{NNH}_{2}$ : demonstrating a hybrid distal-to-alternating pathway for $\mathrm{N}_{2}$ reduction. J. Am. Chem. Soc. 138, 4243-4248 (2016).

39. Del Castillo, T. J., Thompson, N. B. \& Peters, J. C. A synthetic single-site Fe nitrogenase: high turnover, freeze-quench ${ }^{57} \mathrm{Fe}$ Mössbauer data, and a hydride resting state. J. Am. Chem. Soc. 138, 5341-5350 (2016).

40. Arashiba, K., Miyake, Y. \& Nishibayashi, Y. A molybdenum complex bearing PNP-type pincer ligands leads to the catalytic reduction of dinitrogen into ammonia. Nat. Chem. 3, 120-125 (2011).

41. Kuriyama, S. et al. Catalytic formation of ammonia from molecular dinitrogen by use of dinitrogen-bridged dimolybdenum-dinitrogen complexes bearing PNP-pincer ligands: remarkable effect of substituent at PNP-pincer ligand. J. Am. Chem. Soc. 136, 9719-9731 (2014).

42. Kuriyama, S. et al. Nitrogen fixation catalyzed by ferrocene-substituted dinitrogen-bridged dimolybdenum-dinitrogen complexes: unique behavior of ferrocene moiety as redox active site. Chem. Sci. 6, 3940-3951 (2015).

43. Tanaka, H. et al. Unique behaviour of dinitrogen-bridged dimolybdenum complexes bearing pincer ligand towards catalytic formation of ammonia. Nat. Commun. 5, 3737 (2014).

44. Arashiba, K. et al. Catalytic reduction of dinitrogen to ammonia by use of molybdenum-nitride complexes bearing a tridentate triphosphine as catalysts. J. Am. Chem. Soc. 137, 5666-5669 (2015).

45. Hopkinson, M. N., Richter, C., Schedler, M. \& Glorius, F. An overview of N-heterocyclic carbenes. Nature 510, 485-496 (2014).

46. Nolan, S. P. (ed.) N-Heterocyclic Carbenes (Wiley-VCH, 2014).

47. Trnka, T. M. \& Grubbs, R. H. The development of $\mathrm{L}_{2} \mathrm{X}_{2} \mathrm{Ru}=\mathrm{CHR}$ olefin metathesis catalysts: an organometallic success story. Acc. Chem. Res. 34, 18-29 (2001).

48. Ohki, Y. \& Seino, H. N-heterocyclic carbenes as supporting ligands in transition metal complexes of $\mathrm{N}_{2}$. Dalton Trans. 45, 874-880 (2016).

49. Plikhta, A., Pöthig, A., Herdtweck, E. \& Rieger, B. Toward new organometallic architectures: synthesis of carbene-centered rhodium and palladium bisphosphine complexes. Stability and reactivity of $\left[\mathrm{PC}^{\mathrm{BIm}} \mathrm{PRh}(\mathrm{L})\right]\left[\mathrm{PF}_{6}\right]$ pincers. Inorg. Chem. 54, 9517-9528 (2015).

50. Lee, H. M., Zeng, J. Y., Hu, C.-H. \& Lee, M.-T. A new tridentate pincer phosphine/ $N$-heterocyclic carbene ligand: palladium complexes, their structures, and catalytic activities. Inorg. Chem. 43, 6822-6829 (2004)

51. Chiu, P. L. \& Lee, H. M. Chemistry of the $\mathrm{PC}^{\mathrm{NHC}} \mathrm{P}$ ligand: silver and ruthenium complexes, facial/meridional coordination, and catalytic transfer hydrogenation. Organometallics 24, 1692-1702 (2005).

52. Gradert, C., Krahmer, J., Sönnichsen, F. D., Näther, C. \& Tuczek, F. Small molecule activation with molybdenum(0) complexes supported by mixed inidazol-2-ylidene/phosphanyl hybrid ligands-electronic and structural consequences of substituting a phosphane by a carbene group. Eur. J. Inorg. Chem. 2013, 3943-3955 (2013).

53. Gradert, C., Krahmer, J., Sönnichsen, F. D., Näther, C. \& Tuczek, F. Molybdenum(0)-carbonyl complexes supported by mixed benzimidazol-2ylidene/phosphine ligands: influence of benzannulation on the donor properties of the NHC groups. J. Organomet. Chem. 770, 61-68 (2014).

54. Bestgen, S., Gamer, M. T., Lebedkin, S., Kappes, M. M. \& Roesky, P. W. Di- and trinuclear gold complexes of diphenylphosphinoethyl-functionalised imidazolium salts and their N-heterocyclic carbenes: synthesis and photophysical properties. Chem. Eur. J. 21, 601-614 (2015).

55. Gradert, C., Stucke, N., Krahmer, J., Näther, C. \& Tuczek, F. Molybdenum complexes supported by mixed NHC/phosphine ligands: activation of $\mathrm{N}_{2}$ and reaction with $\mathrm{P}(\mathrm{OMe})_{3}$ to the first meta-phosphite complex. Chem. Eur. J. 21, 1130-1137 (2015).

56. Anderson, S. N. \& Richards, R. L. Dinitrogen complexes of tungsten with bulky phosphine co-ligands. Preparation and crystal structures of $\left[\left\{\mathrm{W}\left(\mathrm{N}_{2}\right)_{2}\left(\mathrm{PEt}_{2} \mathrm{Ph}\right)_{3}\right\}_{2}\left(\mu-\mathrm{N}_{2}\right)\right]$, trans $-\left[\mathrm{W}\left(\mathrm{N}_{2}\right)_{2}\left(\mathrm{PEt}_{2} \mathrm{Ph}\right)_{4}\right] \cdot \mathrm{C}_{4} \mathrm{H}_{8} \mathrm{O}$, and $\left[\mathrm{W}\left(\eta^{6}-\mathrm{C}_{6} \mathrm{H}_{5} \mathrm{PPr}_{2}{ }_{2}\right)\left(\mathrm{N}_{2}\right)\left(\mathrm{PPr}_{2}{ }_{2} \mathrm{Ph}\right)_{2}\right]$ and their reactions to give hydrazine or ammonia. J. Chem. Soc. Dalton Trans. 245-252 (1986).

57. Anderson, S. N., Hughes, D. L. \& Richards, R. L. Preparation of mer- $\left[\mathrm{Mo}\left(\mathrm{N}_{2}\right)_{3}\left(\mathrm{PPr}_{2}{ }_{2} \mathrm{Ph}\right)_{3}\right]$ from trans- $\left[\mathrm{Mo}\left(\mathrm{N}_{2}\right)_{2}\left(\mathrm{PPr}_{2}{ }_{2} \mathrm{Ph}\right)_{4}\right]$; its $X$-ray crystal structure, spectroscopic properties, and protonation to give ammonia. J. Chem. Soc. Dalton Trans. 1591-1594 (1986).

58. Ohki, Y., Aoyagi, K. \& Seino, H. Synthesis and protonation of N-heterocycliccarbene-supported dinitrogen complexes of molybdenum(0). Organometallics 34, 3414-3420 (2015)
59. Gusev, D. G. Donor properties of a series of two-electron ligands. Organometallics 28, 763-770 (2009).

60. Gusev, D. G. Electronic and steric parameters of $76 \mathrm{~N}$-heterocyclic carbenes in $\mathrm{Ni}(\mathrm{CO})_{3}(\mathrm{NHC})$. Organometallics 28, 6458-6461 (2009).

61. Weatherburn, M. W. Phenol-hypochlorite reaction for determination of ammonia. Anal. Chem. 39, 971-974 (1967).

62. Glendening, E. D. et al. NBO 5.9 (Theoretical Chemistry Institute, University of Wisconsin, 2009).

63. Mayer, I. Charge, bond order and valence in the AB initio SCF theory. Chem. Phys. Lett. 97, 270-274 (1983).

64. Comas-Vives, A. \& Harvey, J. N. How important is backbonding in metal complexes containing N-heterocyclic carbenes? Structural and NBO analysis. Eur. J. Inorg. Chem. 2011, 5025-5035 (2011).

65. Nelson, D. J. \& Nolan, S. P. Quantifying and understanding the electronic properties of $N$-heterocyclic carbenes. Chem. Soc. Rev. 42, 6723-6753 (2013).

66. Frisch, M. J. et al. Gaussian 09, Revision C.01 (Gaussian, Inc., 2011).

67. Reiher, M., Salomon, O. \& Hess, B. A. Reparametrization of hybrid functionals based on energy differences of states of different multiplicity. Theor. Chem. Acc. 107, 48-55 (2001).

68. Tomasi, J., Mennucci, B. \& Cammi, R. Quantum mechanical continuum solvation models. Chem. Rev. 105, 2999-3094 (2005).

69. Castellani, M. P., Geib, S. J., Rheingold, A. L. \& Trogler, W. C. Synthesis, reactivities, molecular structures, and physical properties of paramagnetic bis(tetraphenylcyclopentadienyl) complexes of vanadium, chromium, cobalt, and nickel. Organometallics 6, 1703-1712 (1987).

70. Clarke, K. \& Rothwell, K. A kinetic study of the effect of substituents on the rate of formation of alkylpyridinium halides in nitromethane solution. J. Chem. Soc. 1960, 1885-1895 (1960).

\section{Acknowledgements}

The present project is supported by CREST, JST. We thank KAKENHI (Nos JP26288044 JP26105708, JP15K13687, JP15H05798 to Y.N., No. JP24109014 to K.Y. and No. JP26888008 to H.T.) from JSPS and MEXT. A.E. and S.K. are recipients of the JSPS Predoctoral Fellowships for Young Scientists. We also thank the Research Hub for Advanced Nano Characterization at The University of Tokyo for X-ray analysis.

\section{Author contributions}

K.Y. and Y.N. directed and conceived this project. A.E., K.A., S.K. and K.N. conducted the experimental work. H.T. and Y.M. conducted the computational work. All authors discussed the results and wrote the manuscript.

\section{Additional information}

Supplementary Information accompanies this paper at http://www.nature.com/ naturecommunications

Competing interests: The authors declare no competing financial interests.

Reprints and permission information is available online at http://npg.nature.com/ reprintsandpermissions/

How to cite this article: Eizawa, A. et al. Remarkable catalytic activity of dinitrogen bridged dimolybdenum complexes bearing NHC-based PCP-pincer ligands toward nitrogen fixation. Nat. Commun. 8, 14874 doi: 10.1038/ncomms14874 (2017).

Publisher's note: Springer Nature remains neutral with regard to jurisdictional claims in published maps and institutional affiliations.

This work is licensed under a Creative Commons Attribution 4.0 International License. The images or other third party material in this article are included in the article's Creative Commons license, unless indicated otherwise in the credit line; if the material is not included under the Creative Commons license, users will need to obtain permission from the license holder to reproduce the material. To view a copy of this license, visit http://creativecommons.org/licenses/by/4.0/

(C) The Author(s) 2017 